\title{
Thermoresponsive Semicrystalline Poly( $\varepsilon$-caprolactone) Networks: Exploiting Cross-linking with Cinnamoyl Moieties to Design Polymers with Tunable Shape Memory
}

\author{
Amit Garle, ${ }^{\dagger}$ Sany Kong, ${ }^{\ddagger}$ Umaprassana Ojha, ${ }^{\ddagger} \S$ and Bridgette M. Budhlall* ${ }^{\dagger}$ \\ ${ }^{\dagger}$ Department of Plastics Engineering and NSF Center for High-Rate Nanomanufacturing and ${ }^{\ddagger}$ Department of Chemistry, University \\ of Massachusetts, Lowell, Massachusetts 01854, United States
}

Supporting Information

\begin{abstract}
The overall goal of this study was to synthesize semicrystalline poly( $\varepsilon$-caprolactone) (PCL) copolymer networks with stimuli-responsive shape memory behavior. Herein, we investigate the influence of a cinnamoyl moiety to design shape memory polymer networks with tunable transition temperatures. The effect of various copolymer architectures (random or ABA triblock), the molecular weight of the crystalline domains, PCL diol, $\left(M_{\mathrm{w}} 1250\right.$ or $2000 \mathrm{~g}$ $\mathrm{mol}^{-1}$ ) and its composition in the triblock ( 50 or $80 \mathrm{~mol} \%$ ) were also investigated. The polymer microstructures were confirmed by NMR, DSC, WAXS and UV-vis spectroscopic techniques. The thermal and mechanical properties and the cross-linking density of the networks were characterized by DSC, tensile testing and solvent swelling, respectively. Detailed thermomechanical investigations conducted using DMA showed that shape memory behavior was obtained only in the ABA triblock copolymers. The best shape memory fixity, $R_{\mathrm{f}}$ of $\sim 99 \%$ and shape recovery, $R_{\mathrm{r}}$ of $\sim 99 \%$ was obtained when PCL diol

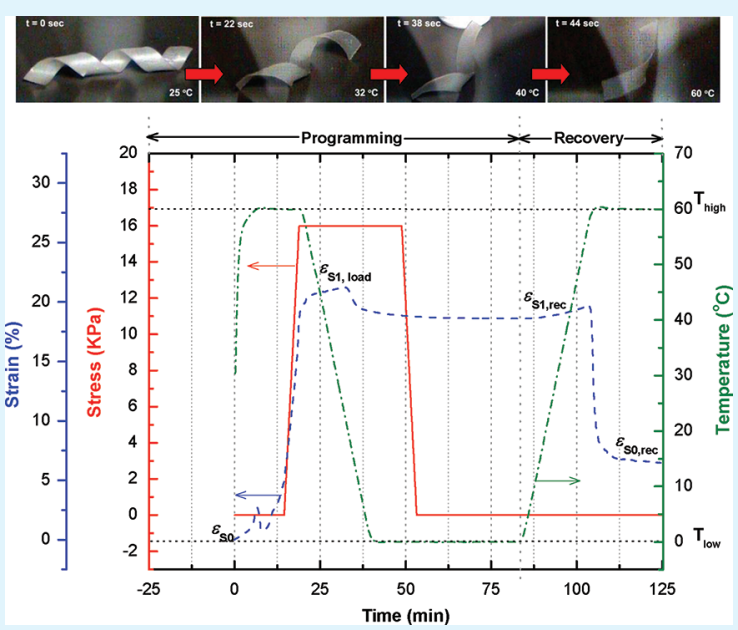
with $M_{\mathrm{w}} 2000 \mathrm{~g} \mathrm{~mol}^{-1}$ was incorporated in the triblock copolymer at a concentration of $50 \mathrm{~mol} \%$. The series of triblock copolymers with PCL at $50 \mathrm{~mol} \%$ also showed mechanical properties with tunable shape memory transition temperatures, ranging from $54{ }^{\circ} \mathrm{C}$ to close to body temperature. Our work establishes a general design concept for inducing a shape memory effect into any semicrystalline polyester network. More specifically, it can be applied to systems which have the highest transition temperature closest to the application temperature. An advantage of our novel copolymers is their ability to be cross-linked with UV radiation without any initiator or chemical cross-linker. Possible applications are envisioned in the area of endovascular treatment of ischemic stroke and cerebrovascular aneurysms, and for femoral stents.
\end{abstract}

KEYWORDS: poly(E-caprolactone), cinnamate group, semicrystalline polymer networks, shape memory polymer, stents, biomedical device, stimuli-responsive polymers

\section{INTRODUCTION}

As the field of medicine and biotechnology progresses, the demand for novel biomaterials with multiple functions is increasing. This demand for multifunctional biomaterials with biodegradation and biocompatibility capabilities has led to great advances in the field of macromolecular design. Development of new materials and proving their suitability for a medical application is a very expensive and time-consuming process. Modification of existing well-established materials to induce additional novel properties while retaining their useful properties appears to be a useful strategy. Materials that have been used as biomaterials include polyurethanes and polyesters. Of these, polyesters are well-established materials with various FDA-approved commercial products such as sutures (Monocryl, Caprosyn, Novafil).
Shape memory polymers belong to a class of smart materials that change their shape when exposed to an external stimulus, which can be light, ${ }^{1-3}$ heat, ${ }^{4-6} \mathrm{pH}^{7}$ magnetic field, ${ }^{8}$ moisture, ${ }^{9}$ or solvent. ${ }^{10}$ The requirements for a material to exhibit a thermally responsive shape memory effect are a transition temperature and a force for recovery to its permanent shape. Permanent shape is defined as the shape obtained by chemical or physical (entanglement of chains) cross-linking. At the transition temperature, the material changes from the temporary programmed shape to its permanent shape. The driving force is the work done on the material during programming of the temporary shape. (This phenomenon is

Received: August 25, 2011

Accepted: January 17, 2012

Published: January 17, 2012 
essentially the same as deforming an elastomer by stress ${ }^{11}$ and the recovery of the shape on release of the applied stress except that the final deformed state in shape memory polymers is frozen). The transition temperatures can either be the glass transition $\left(T_{\mathrm{g}}\right)$ or melting temperatures $\left(T_{\mathrm{m}}\right)$.

$\varepsilon$-Caprolactone $(\mathrm{CL})$ is a cyclic lactone monomer that can be polymerized by anionic ${ }^{12,13}$ or cationic ${ }^{14,15}$ polymerization so that polymers with controlled structure and functionality can be synthesized. CL modification can be conducted directly at the $\alpha$-carbon by electrophilic substitution via formation of an anion using a strong base or by synthesizing functionalized CL using Baeyer-Villiger oxidation. Previously, CL has been modified with functional groups such as halogens (bromide, ${ }^{16}$ chloride, ${ }^{17}$ iodide $^{18}$ ), azide, ${ }^{19}$ ATRP initiators, ${ }^{20}$ methylene, $^{21}$ and hydroxyl. ${ }^{22}$

Various approaches have been used to introduce a shape memory effect in poly $(\varepsilon$-caprolactone) (PCL). Recent examples are three-arm triol PCL-based poly(urethanes), ${ }^{23}$ polyhydroxybutyrate $^{24}$ and poly(pentadecalactone)-modified PCL. ${ }^{25}$ Lendlein, ${ }^{26}$ et al., synthesized polymer networks of various monomers to make polymers with different transition temperatures. In his work, PCL based polyurethanes with PCL $\mathrm{diol}^{27} /$ triol $^{23}$ as the soft segment and aromatic isocyanates as the hard segment were synthesized to study the shape memory effect. The shape memory effect in these cases was due to the phase separation of different components with a higher transition temperature used to set the permanent shape and a lower transition temperature used for the shape memory transition.

In addition to demonstrations of the shape memory effect in block copolymers, cross-linked systems have also been shown to exhibit shape memory. The photo-cross-linking of PCL to confer SMP properties have previously been reported by Nagata et al. Chain extension of low molecular weight PCL, ${ }^{28-30}$ poly(L-lactide) (PLLA), ${ }^{28,31,32}$ and PEG $^{33-35}$ polymers with photo-cross-linkable groups were reported. Chain extension of $\alpha, \omega$-dihydroxy PCL with coumarin dichloride was performed to form PCL with intermittently pendent coumarin groups which can be UV cross-linked. Radiation $^{36,37}$ cross-linking of PCL and PCL blends with poly(vinylmethylsiloxane) has also been reported to confer shape memory effect. Ritter ${ }^{21,38}$ et al., modified $\gamma$-butyrolactone and CL with a methylene group and copolymerized it with CL to obtain copolymers that can be cross-linked by radical copolymerization. Similarly, Mather ${ }^{39}$ et al. reported synthesis of shape memory polymers using PCL dimethacrylates crosslinked by tetrathiol. These cross-linking agents persist in the final polymer and may not be suitable for biomedical applications. The shape memory effect can also be derived by obtaining a cross-linked PCL in POSS/PCL systems ${ }^{40}$ as well as networks of PCL blends. ${ }^{41}$ The cross-linking helped in maintaining the permanent shape, whereas the melting of the crystalline domains in the polymer provided the thermal transition.

The incorporation of cinnamoyl groups into the polymer chains would be a convenient way to produce cross-linkable biodegradable polymers since cinnamates can undergo cis/trans isomerization and $[2+2]$ cycloaddition when irradiated by UV light of greater than $260 \mathrm{~nm}$ wavelength. ${ }^{42}$ It is expected that the cinnamate group will be biodegradable as it is linked to the polymer by a hydrolyzable ester linkage. In fact, the cinnamoyl group is metabolized in the body and has been proven to be nontoxic, $^{43,44}$ which has been evidenced by the fact that cinnamate esters have been used as food ingredients for many years. A few biodegradable hydrogels have been prepared by photo-cross-linking hydrophilic copolymers containing the pendent or terminal cinnamoyl group in the polymer chains. The UV cross-linking of the cinnamate group is not effective for thick samples ( $>$ few $\mathrm{mm}$ ) because of limited penetration of the UV light. This cross-linking reaction however can be used for thin samples $(<\mathrm{few} \mathrm{mm})$ which are suitable for biomedical applications such as stents and catheters. This cycloaddition reaction has been previously used to synthesize high-performance thermoplastic polymers ${ }^{45}$ and liquid crystalline biopolymers. $^{46-48}$

The novelty of our design is in using a single monomer, functionalizing it to synthesize a new monomer that introduces shape memory effect in PCL. Of significance is our synthesis of $\varepsilon$-caprolactone functionalized with a cinnamate group, reported here for the first time. Specifically we utilized cinnamate functional groups to modify CL in order to impart rapid shape memory response and stimuli-responsive properties to PCLbased copolymers. In this article, we describe the synthesis and characterization of thermoresponsive PCL-PCCL-PCL (ABA) copolymer networks with tunable shape memory response. As a proof-of-principle, the PCL molecular weight, composition, and polymer architecture (random or ABA triblock) was systematically varied to determine the effect of these parameters on the thermomechanical properties and the capability of tuning the transition temperature of the shape memory response.

Some advantages of our SMP network design is the use of the cinnamate functionality to control the cross-linking density via UV light without the use of any initiators or chemical crosslinkers which may remain in the final polymer. Although the degradation products of our copolymer networks are expected to be biocompatible, subsequent studies will focus on biodegradation and biocompatibility.

\section{EXPERIMENTAL SECTION}

2.1. Materials. Cinnamoyl chloride (Aldrich, 98\%), 1,4-cyclohexanediol (Alfa Aesar, 98+\%), pyridinium chlorochromate (Alfa Aesar, 98\%), triethylamine (Alfa Aesar, 99\%), 3-chloroperoxybenzoic acid (Alfa Aesar, 70-75\%), ethyl acetate (Aldrich, $\geq 99.5 \%$ ), triethylene glycol (Aldrich, 99.8\%), hydrochloric acid (Mallinckrodt chemicals, 36.5-38\%), sodium chloride (Aldrich, $\geq 99.5 \%$ ), methylene chloride (Aldrich, $\geq 99.5 \%$ ), magnesium sulfate (Fluka analytical, 98\%), $\varepsilon$-caprolactone (Alfa Aesar, 99\%), toluene (Aldrich, 99.9\%), tin(II) 2-ethylhexanoate $\left(\mathrm{Sn}(\mathrm{Oct})_{2}\right.$, Aldrich, 95\%), acetic acid (Aldrich, 99.7\%), hexane (Aldrich, $\geq 99.8 \%$ ), tetrahydrofuran, (THF, Aldrich, 99.9\%). PCL diol, $M_{\mathrm{w}}=1250$ and $2000 \mathrm{~g} \mathrm{~mol}^{-1}$ (Polysciences), THF and toluene were distilled over sodium metal and benzophenone under a nitrogen atmosphere. Methylene chloride was distilled before the reaction. All other chemicals were used as received.

2.2.1. Synthesis of Cinnamate-Modified $\varepsilon$-Caprolactone (CCL). Esterification of 1,4-Cyclohexandiol to Synthesize 3Phenyl-acrylic Acid 4-hydroxyl-cyclohexyl Ester (A). The synthesis is depicted in Scheme 1 and was conducted as follows. 1,4Cyclohexanediol (20.0 g, $172.4 \mathrm{mmol})$ was dissolved in dichloromethane $(200 \mathrm{~mL})$. Cinnamoyl chloride $(7.2 \mathrm{~g}, 43.1$ $\mathrm{mmol}$ ) dissolved in $50 \mathrm{~mL}$ dichloromethane was then slowly added. After $2 \mathrm{~h}$ of stirring, triethyl amine $(5.3 \mathrm{~g}, 52 \mathrm{mmol})$ was added slowly. After $48 \mathrm{~h}$ of stirring, the solution was washed three times with dilute $\mathrm{HCl}(1 \mathrm{M})$ and at least two more times with $\mathrm{H}_{2} \mathrm{O}$ before it was dried over $\mathrm{MgSO}_{4}$ and filtered. The product was then dissolved in methanol, resulting in precipitation of the byproduct. After evaporating the solvents, the product was a yellow-orange viscous liquid, which was used without further purification. Yield: $25-40 \%$. ${ }^{1} \mathbf{H}$ NMR 
$\left(\mathrm{CDCl}_{3}\right): \delta(\mathrm{ppm})=5.1\left(\mathrm{~m}, 4 \mathrm{H},-\mathrm{CH}_{2}-\mathrm{CH}(\mathrm{O}-) \mathrm{CH}_{2}-\right), 2.0$ $\left(\mathrm{m}, 4 \mathrm{H},-\mathrm{CH}_{2}-\mathrm{CH}(\mathrm{OH}) \mathrm{CH}_{2^{-}}\right), 3.7(\mathrm{~m}, 1 \mathrm{H},-\mathrm{C}(\mathrm{HO}) \mathrm{H}-), 5.3$ $\left(\mathrm{m}, 1 \mathrm{H},-\mathrm{CH}_{2}-\mathrm{CH}(\mathrm{O}-) \mathrm{CH}_{2}-\right), 6.5(\mathrm{~d}, 1 \mathrm{H},-\mathrm{OC}(\mathrm{O})-$ $\mathrm{CH}=\mathrm{CH}-), 7.7(\mathrm{~d}, 1 \mathrm{H},-\mathrm{OC}(\mathrm{O})-\mathrm{CH}=\mathrm{CH}-) 7.6(\mathrm{~d}, 2 \mathrm{H}$, aromatic) $7.4\left(\mathrm{~m}, 3 \mathrm{H}\right.$, aromatic). ${ }^{13} \mathbf{C}$ NMR $\left(\mathbf{C D C l}_{3}\right): \delta(\mathrm{ppm})$ $=27\left(-\mathrm{CH}_{2}-\mathrm{CH}(\mathrm{O}-) \mathrm{CH}_{2}-\right), 31\left(-\mathrm{CH}_{2}-\mathrm{CH}(\mathrm{OH}) \mathrm{CH}_{2-}\right), 68$ $(-\mathrm{C}(\mathrm{HO}) \mathrm{H}-), \quad 70\left(-\mathrm{CH}_{2}-\mathrm{CH}(\mathrm{O}-) \mathrm{CH}_{2}-\right), 118$ (-OC(O)$\mathrm{CH}=\mathrm{CH}-$ ), $127-130$ (aromatic), $134(-\mathrm{CH}=\mathrm{CH}-\mathrm{C}-), 144$ $(-\mathrm{OC}(\mathrm{O})-\mathrm{CH}=\mathrm{CH}-), 167(-\mathrm{OC}(\mathrm{O})-\mathrm{CH}=\mathrm{CH}-)$.

2.2.2. Oxidation of $(A)$ to Synthesize 3-Phenyl-acrylic Acid 4-Oxocyclohexyl Ester (B). Pyridinium chlorochromate (PCC) (19.7 g, 91.5 $\mathrm{mmol})$ was added to a solution of (A) $(15.0 \mathrm{~g}, 61 \mathrm{mmol})$ in dichloromethane $(150 \mathrm{~mL})$. The mixture was stirred for $12 \mathrm{~h}$. The reaction mixture was then added to silica gel $(30.0 \mathrm{~g})$ and the solvent was evaporated. The product was purified using column chromatography (silica gel using hexane/EtOAc gradient as eluent) to give a white crystalline powder. Yield: $80 \%$. ${ }^{1} \mathbf{H}$ NMR $\left(\mathbf{C D C l}_{3}\right): \delta(\mathrm{ppm})=$ $2.2\left(\mathrm{~m}, 4 \mathrm{H},-\mathrm{CH}_{2}-\mathrm{CH}(\mathrm{O}-) \mathrm{CH}_{2}-\right), 2.4$ and $2.6\left(\mathrm{~m}, 4 \mathrm{H},-\mathrm{CH}_{2^{-}}\right.$ $\left.\mathrm{CH}(\mathrm{OH}) \mathrm{CH}_{2^{-}}\right), 5.3\left(\mathrm{~m}, 1 \mathrm{H},-\mathrm{CH}_{2}-\mathrm{CH}(\mathrm{O}-) \mathrm{CH}_{2}-\right), 6.5(\mathrm{~d}, 1 \mathrm{H}$, $-\mathrm{C}(\mathrm{O})-\mathrm{CH}=\mathrm{CH}-), 7.7(\mathrm{~d}, 1 \mathrm{H},-\mathrm{C}(\mathrm{O})-\mathrm{CH}=\mathrm{CH}-) 7.6(\mathrm{~d}, 2 \mathrm{H}$, aromatic) $7.4\left(\mathrm{~m}, 3 \mathrm{H}\right.$, aromatic). ${ }^{13} \mathbf{C ~ N M R ~}\left(\mathbf{C D C l}_{3}\right): \delta(\mathrm{ppm})=31$ $\left(-\mathrm{CH}_{2}-\mathrm{CH}(\mathrm{O}-) \mathrm{CH}_{2}-\right), 37\left(-\mathrm{CH}_{2}-\mathrm{CH}(\mathrm{OH}) \mathrm{CH}_{2}-\right), 69\left(-\mathrm{CH}_{2}-\mathrm{CH}-\right.$ $\left.(\mathrm{O}-) \mathrm{CH}_{2}-\right), 118(-\mathrm{OC}(\mathrm{O})-\mathrm{CH}=\mathrm{CH}-), 127-130$ (aromatic), 134 $(-\mathrm{CH}=\mathrm{CH}-\mathrm{C}-), 154(-\mathrm{OC}(\mathrm{O})-\mathrm{CH}=\mathrm{CH}-), 167(-\mathrm{OC}(\mathrm{O})-\mathrm{CH}=\mathrm{CH}-$ ), $210\left(-\mathrm{CH}_{2}-\mathrm{C}(\mathrm{O})-\mathrm{CH}_{2}-\right)$.

2.2.3. Baeyer-Villiger Oxidation of (B) to Synthesize 3-Phenyl Acrylic Acid 4-Oxo-oxepan-4-yl Ester (C). (B) (10.0 g, $38.5 \mathrm{mmol}$ ) was dissolved in $50 \mathrm{~mL}$ of dichloromethane and added dropwise into a solution of 3-chloroperoxybenzoic acid (99.3 g, $42.4 \mathrm{mmol}$ ) in dichloromethane $(50 \mathrm{~mL})$. The mixture was stirred for $24 \mathrm{~h}$ and then filtered. The resulting solution was washed twice with $\mathrm{NaHCO}_{3}(2 \mathrm{M})$ and once with brine. The extracted product was then purified by column chromatography (by silica gel using hexane/EtOAc gradient as eluent). The monomer was obtained as a white crystalline powder. Yield: $70 \% .{ }^{1} \mathbf{H}$ NMR $\left(\mathbf{C D C l}_{3}\right): \delta(\mathrm{ppm})=2.6$ and $3.0\left(\mathrm{~m}, 4 \mathrm{H},-\mathrm{CH}_{2^{-}}\right.$ $\left.\mathrm{C}(\mathrm{O}) \mathrm{OCH}_{2}-\right), 4.2$ and $4.6\left(\mathrm{~m}, 4 \mathrm{H},-\mathrm{CH}_{2}-\mathrm{C}(\mathrm{O}) \mathrm{OCH}_{2}-\right), 2.1$ and $2.2\left(\mathrm{~m}, 4 \mathrm{H},-\mathrm{CH}_{2}-\mathrm{CH}(\mathrm{O}-) \mathrm{CH}_{2^{-}}\right), 5.3\left(\mathrm{~m}, 1 \mathrm{H},-\mathrm{CH}_{2}-\mathrm{CH}(\mathrm{O}-)-\right.$ $\left.\mathrm{CH}_{2}-\right)$, $6.5(\mathrm{~d}, 1 \mathrm{H},-\mathrm{C}(\mathrm{O})-\mathrm{CH}=\mathrm{CH}-), 7.7(\mathrm{~d}, 1 \mathrm{H},-\mathrm{C}(\mathrm{O})-\mathrm{CH}=$ $\mathrm{CH}-) 7.6\left(\mathrm{~d}, 2 \mathrm{H}\right.$, aromatic) $7.4\left(\mathrm{~m}, 3 \mathrm{H}\right.$, aromatic). ${ }^{13} \mathrm{C}$ NMR$\left(\mathrm{CDCl}_{3}\right): \delta(\mathrm{ppm})=27-28\left(-\mathrm{CH}_{2}-\mathrm{CH}(\mathrm{O}-) \mathrm{CH}_{2}-\right), 34\left(-\mathrm{CH}_{2}-\right.$ $\left.\mathrm{C}(\mathrm{O}) \mathrm{OCH}_{2}-\right), 63\left(-\mathrm{CH}_{2}-\mathrm{C}(\mathrm{O}) \mathrm{OCH}_{2}-\right), 70 \quad\left(-\mathrm{CH}_{2}-\mathrm{CH}(\mathrm{O}-)-\right.$ $\left.\mathrm{CH}_{2}-\right), 118(-\mathrm{OC}(\mathrm{O})-\mathrm{CH}=\mathrm{CH}-), \quad 127-130$ (aromatic), 134 $(-\mathrm{CH}=\mathrm{CH}-\mathrm{C}-), 146 \quad(-\mathrm{OC}(\mathrm{O})-\mathrm{CH}=\mathrm{CH}-), 167 \quad(-\mathrm{OC}(\mathrm{O})-\mathrm{CH}=$ $\mathrm{CH}-), 175\left(-\mathrm{CH}_{2}-\mathrm{C}(\mathrm{O})-\mathrm{CH}_{2}-\right)$. The structure of the cinnamate modified caprolactone (CCL) was also confirmed by analysis of the functional groups using ATR IR as shown in Figure S.13 (Supporting Information). CCL exhibited characteristic absorptions of the $\mathrm{C}=\mathrm{C}$ double bond in the ring $\left(1640 \mathrm{~cm}^{-1}\right)$ as well as the characteristic absorptions of ester attached to $\mathrm{C}=\mathrm{C}$ at 1218 and $1072 \mathrm{~cm}^{-1}$ and the cyclic ester at $1740 \mathrm{~cm}^{-1}$.

2.2.4. Ring-Opening Polymerization of $C L$ and $C C L$ Using $\mathrm{Sn}(\mathrm{OCt})_{2}$. The polymerization was depicted in Scheme 2 and was conducted as follows. Triethylene glycol $(6.3 \mathrm{mg}, 0.042 \mathrm{mmol})$ and $\mathrm{CL}(5 \mathrm{~g}, 43.86 \mathrm{mmol})$ in toluene were added via a syringe into a 100 $\mathrm{mL}$ 3-neck round-bottom flask equipped with a stir bar. After a toluene solution of $\mathrm{Sn}(\mathrm{Oct})_{2}$ (1 mol \% of carbonyl group, $177.63 \mathrm{mg}, 0.44$ $\mathrm{mM}$ ) was added, the flask as evacuated for more than $2 \mathrm{~h}$. Then the flask was filled with nitrogen gas. Toluene ( $10 \mathrm{~mL}$ per $\mathrm{g}$ of monomer) was then added and the reaction flask was immersed in an oil bath at $110{ }^{\circ} \mathrm{C}$ for $24 \mathrm{~h}$ ( $48 \mathrm{~h}$ for PCCL) to allow polymerization to occur. The reaction was quenched by the addition of $0.3 \mathrm{M}$ acetic acid aqueous solution. The flask was then evacuated until a viscous solution was obtained. The reaction mixture was dissolved in tetrahydrofuran and the polymer was precipitated using cold methanol. After filtration and drying in a vacuum at room temperature for $48 \mathrm{~h}$, the polymer was characterized by NMR, ATR-IR, GPC, DSC, and WAXS.

2.3.1. Characterization Methods. Microstructure and Molecular Characterization. ${ }^{1} \mathrm{H}$ NMR and ${ }^{13} \mathrm{C}$ NMR spectroscopy for structural analysis was performed using a Bruker $500 \mathrm{MHz}$ spectrometer using $\mathrm{CDCl}_{3}$ (Cambridge Isotope Laboratories,
Inc.) as a lock solvent. Fourier-transform infrared (FTIR) attenuated total reflectance (ATR) measurements were taken on a Thermo Scientific Nicolet 4700 with a Smart Orbit ATR accessory to further confirm the functional groups of the cinnamate modified caprolactone and those of the copolymers. Molecular weight and polydispersity indices $\left(\left(M_{\mathrm{w}} / M_{\mathrm{n}}\right)\right.$ or PDI's) were determined by gel permeation chromatography (GPC) in tetrahydrofuran (THF) $\left(1.0 \mathrm{~mL} \mathrm{~min}{ }^{-1}\right)$ using a PL GPC 50 system equipped with two PL Resipore columns (3 $\mu \mathrm{m}, 300 \mathrm{~mm} \times 7.5 \mathrm{~mm}$ ) and an online viscometer detector, along with a differential refractive index (dRI) detector to directly obtain molecular weights from a universal calibration curve.

2.3.2. Thermal Analysis. Thermal characterization of the polymers was conducted using a differential scanning calorimeter (DSC) (TA Instruments, DSC-Q 200). The characterization was performed with three cycles of heat-cool-heat in the temperature range of -100 to 170 ${ }^{\circ} \mathrm{C}$ with both the heating and cooling rate of $10{ }^{\circ} \mathrm{C} \mathrm{min}-1$ under a nitrogen purge. The second heating cycle was used to analyze the calorimetric data (via TA Universal Analysis software) in order to determine the glass transition temperature $\left(T_{\mathrm{g}}\right)$, melting transition $\left(T_{\mathrm{m}}\right)$ and heat of fusion $(\Delta H)$. The crystallinity, $X_{\mathrm{c}}^{\mathrm{D}}$, for each sample was calculated from the heat of melting $\left(\Delta H_{\mathrm{m}}\right)$ measured by DSC using the expression:

$$
X_{\mathrm{c}}^{\mathrm{D}}=\Delta H_{\mathrm{m}} / w_{\mathrm{CL}} \Delta H_{\mathrm{m}, \mathrm{CL}}
$$

where $\left(\Delta H_{\mathrm{m}, \mathrm{CL}}\right)$ is $135 \mathrm{~J} \mathrm{~g}^{-1}$ and is the theoretical heat of melting for perfectly crystalline poly $(\varepsilon$-caprolactone $)$ and $w_{\mathrm{CL}}$ is the weight fraction of CL in the copolymer.

2.3.3. Wide-Angle X-ray Diffraction Analysis. Wide angle X-ray scattering (WAXS) experiments were performed with a Scintag XDS$2000 \theta-\theta$ wide-angle X-ray diffractometer. Scans were taken from 10 to $40^{\circ} 2 \theta$ at a rate of $2^{\circ} \mathrm{min}^{-1}$, with a $\mathrm{Cu}-\mathrm{K} \alpha$ source $(\lambda=1.54 \AA)$ operating with an accelerating voltage of $45 \mathrm{kV}$ and a current of $40 \mathrm{~mA}$ (with $2 \mathrm{~mm}$ and $1 \mathrm{~mm}$ scatter and divergent slits, respectively) and a liquid nitrogen cooled solid state Ge detector (with $0.5 \mathrm{~mm}$ and 0.2 $\mathrm{mm}$ scatter and receiving slits, respectively). All samples were in the form of films with thicknesses of hundreds of micrometers placed atop a polished, miscut single crystal quartz substrate (The Gem Dugout, State College, PA) to minimize background intensity. Following data collection, the background intensity was subtracted via manual spline curve fitting, and Lorentz polarization, and constant beam area corrections were applied to the data prior to profile fitting. For profile fitting, a Pearson VII profile was used, with all peaks given equal weight and with the $K \alpha 2$ contribution included in the profile fit, as the $\mathrm{K} \alpha 2$ contribution was not stripped from the data. Peaks were inserted manually, and profile fitting was performed until the fit could not be improved. The reported error in the final profile fits was in the range of 0.05 to 0.06 in all cases, indicating a good fit. Peaks with large fullwidth-half-maximum (fwhm) values (in the range of $4-7^{\circ}$ in this case) were assigned to the amorphous polymer while peaks with smaller fwhm values (always less than $1.7^{\circ}$ and generally much less than $1^{\circ}$ in this case) were assigned to the crystalline polymer, giving rise to peak assignments consistent with other reports in the literature presenting wide-angle X-ray diffraction patterns for $\operatorname{poly}(\varepsilon$-caprolactone $) .{ }^{49-54}$

The degree of crystallinity, $X_{c}^{X}$, for each sample was calculated by taking the sum of the areas of all the crystalline peak(s) and dividing that sum by the sum of the areas of all peaks (crystalline plus amorphous halo). It is assumed that the polymers are macroscopically isotropic (i.e., on average) in terms of crystallite shape, size, and orientation.

2.3.4. Photocuring: Preparation of Polymer Networks by UVCross-linking. Polymer films were made by means of compression molding in a $230 \mu \mathrm{m}$ thin Teflon coated aluminum sheet with a $5 \mathrm{~cm}$ $\times 5 \mathrm{~cm}$ area cutout from the sheet. The compression molding was performed at 60 to $100{ }^{\circ} \mathrm{C}$ with a pressure of approximately $10 \mathrm{MPa}$. Films were then allowed to cool under pressure in the mold. The obtained films were of thickness $200 \pm 20 \mu \mathrm{m}$, measured using a Vernier caliper. Photocuring of polymers was performed with a UV 


\section{Scheme 1. Synthesis of Cinnamate-Modified $\varepsilon$-Caprolactone (CCL) Monomer}

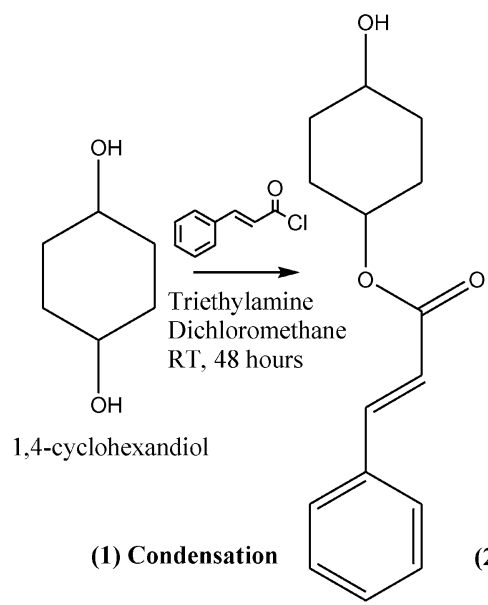

A<smiles>[R10]O[Na]</smiles>

B

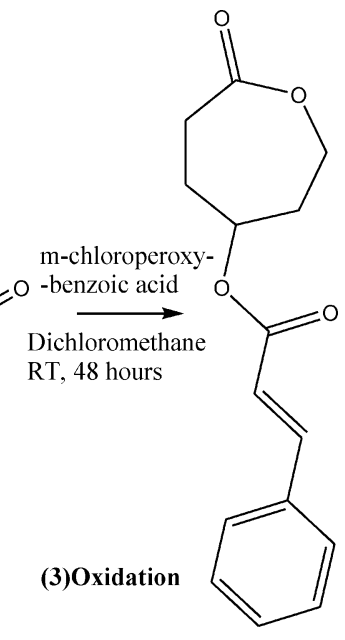

C

Scheme 2. Polymerization Scheme Depicting the Synthesis of Homopolymers of (a) Modified and (b) Unmodified $\varepsilon$ Caprolactone and the Copolymers in a (c) Random and (d) Block Architecture, Respectively

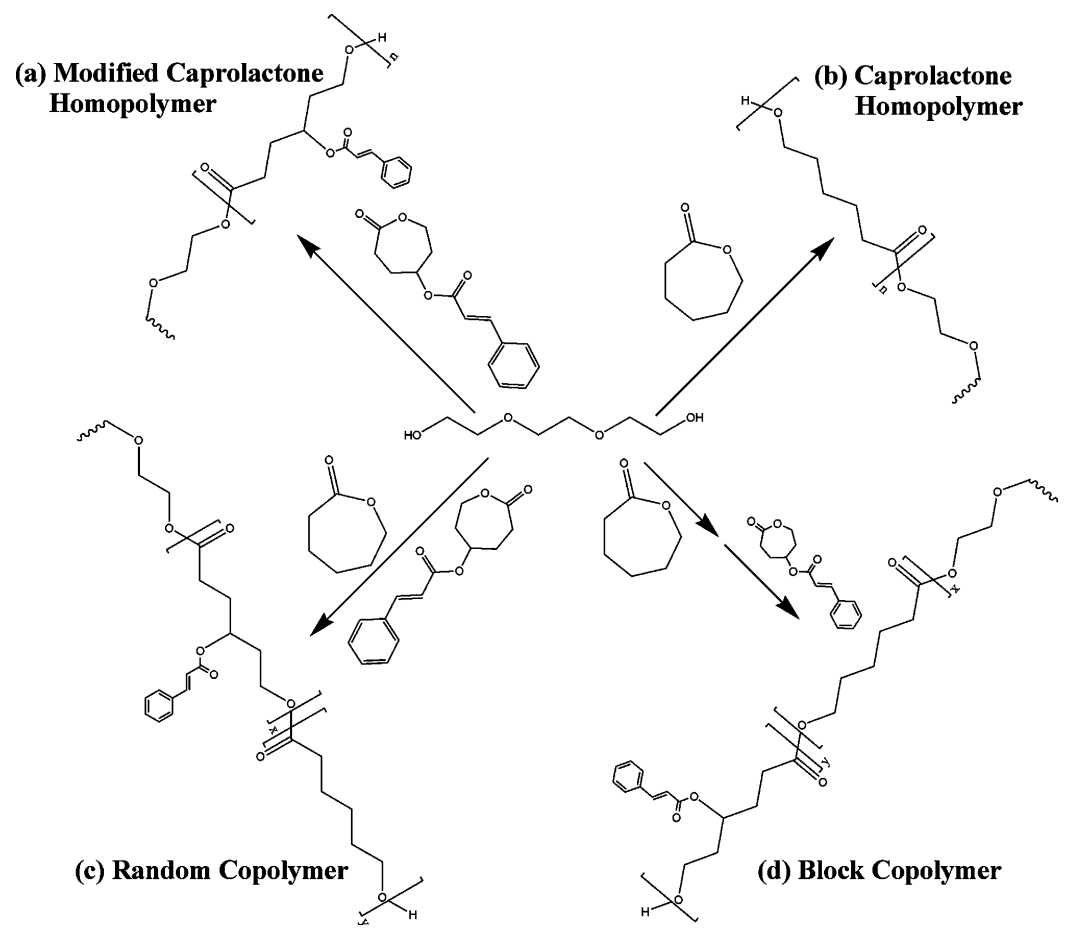

lamp (Dymax corp., BlueWave 200) under a light guide with the sample placed at a distance of $10 \mathrm{~cm}$ below the lamp. The intensity of $\mathrm{UV}$ radiation on the sample was measured to be $40 \mathrm{~mW} \mathrm{~cm}{ }^{-2}$. Films were exposed to UV radiation for $1 \mathrm{~h}$ on each side with the film being flipped every $15 \mathrm{~min}$ to form a network structure and to ensure uniform curing on each side. The curing kinetics of the polymer was studied using an Agilent 8453 photodiode array UV-vis spectrophotometer. Thin films of each polymer were cast on a quartz slide. After evaporation of the solvent, the films were exposed to UV light, wavelength, $\lambda>260 \mathrm{~nm}$ and periodically the UV-vis spectrum of the film was recorded to study the extent of curing by characterization of the cinnamate group.

2.3.5. Extent of Cross-linking (Cross-linking Density) or Gel Content of Polymers. To evaluate the extent of cross-linking or network formation (cross-linking density) by the cycloaddition reaction, we conducted gel fraction measurements by first weighing and then immersing a small cured film in acetone with constant agitation in a shaker. To determine the gel content, the cross-linked films were cut into strips and weighed $\left(W_{\mathrm{i}}\right)$. The films were then immersed in acetone for 2 days to ensure that the un-cross-linked free polymers as well as unreacted monomers were extracted. The swollen films were then removed and allowed to dry under vacuum until a constant weight $\left(W_{\mathrm{f}}\right)$ was obtained. The gel content was calculated according to:

$$
G(\%)=\frac{W_{\mathrm{f}}}{W_{\mathrm{i}}} 100
$$

as $100\left(W_{\mathrm{f}} / W_{\mathrm{i}}\right)$. At least 2 samples of each polymer were analyzed and the average values are listed in Table 2 .

2.3.6. Static Mechanical Properties. Static tensile properties (Young's modulus, ultimate tensile strength, and elongation) were measured at room temperature $\left(22^{\circ} \mathrm{C}\right)$ and at atmospheric conditions 
Scheme 3. Schematic of Proposed Mechanism for Structural Changes in the Polymer during Shape Memory Transformation; PCL segments Form the Crystalline Domains, whereas PCCL Segments Form the Amorphous Domains
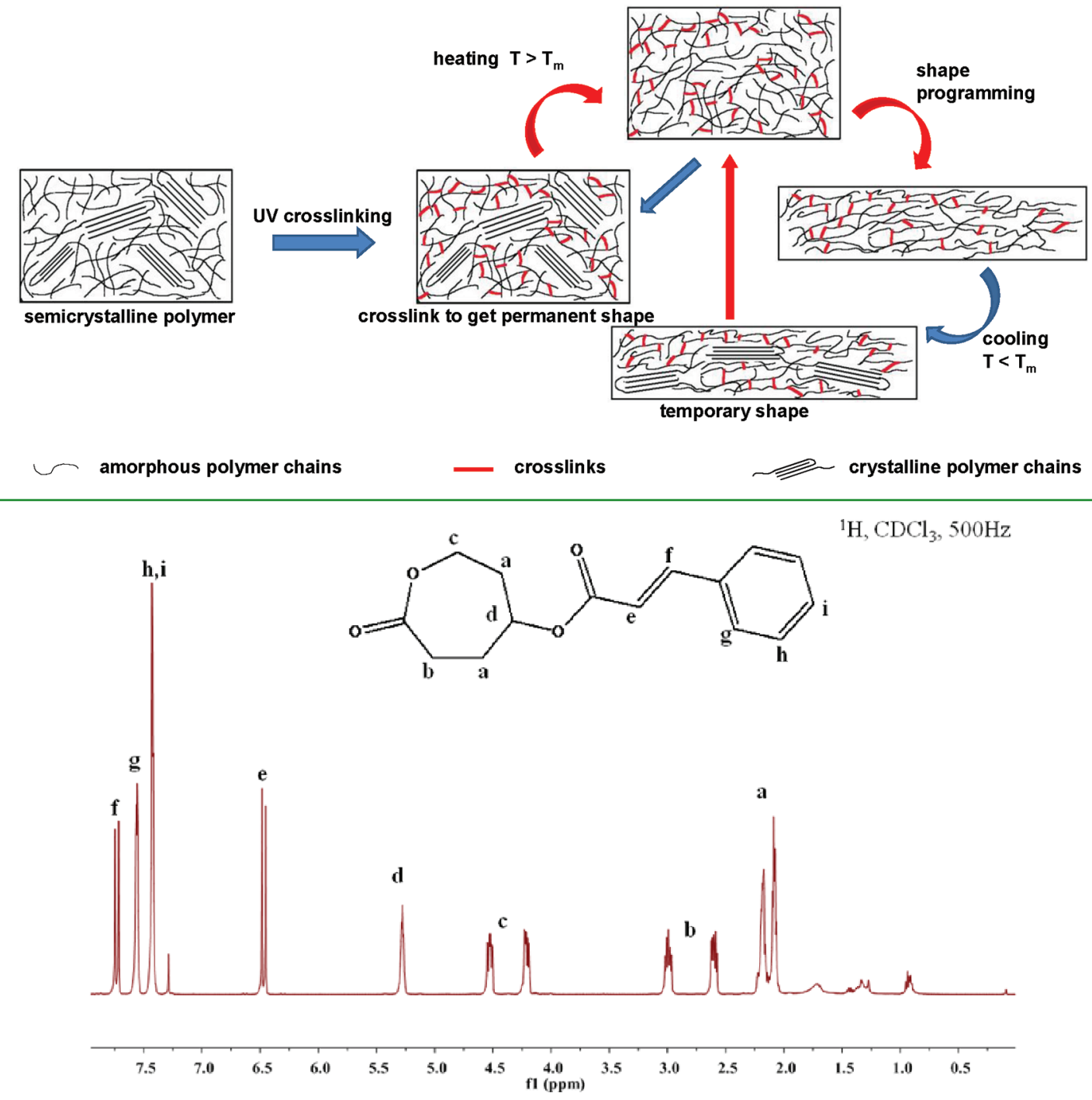

Figure 1. ${ }^{1} \mathrm{H}$ NMR spectrum of cinnamate modified $\varepsilon$-caprolactone (CCL) with peak $\mathbf{d}$ at $5.3 \mathrm{ppm}$ confirming the attachment of the cinnamate group.

using an Instron universal testing machine (Instron 4400R, load cell $250 \mathrm{~N}$ ). The cross-linked films were cut into strips of dimension 30 $\mathrm{mm}$ (length) $\times 2 \mathrm{~mm}$ (width) $\times 0.2 \mathrm{~mm}$ (thickness). All samples were kept at room temperature and under atmospheric conditions before testing. The gap between the jaws was maintained at $25 \mathrm{~mm}$ and the test was performed at a strain rate of $5 \mathrm{~mm} \mathrm{~min}^{-1}$. To determine the mechanical properties, we tested at least 5 samples, and the values are given as average value \pm standard deviation.

2.3.7. Dynamic Mechanical Analysis and Shape Memory Characterization. Linear viscoelastic thermoechanical properties of the polymers were determined using a dynamic mechanical analyzer (DMA) (TA Instruments, Model Q800). The DMA was employed in tensile mode with a preload force of $1 \mathrm{mN}$, an oscillation amplitude of $5 \mu \mathrm{m}(<0.18 \%)$, static stress/dynamic stress amplitude ratio (force tracking) of $110 \%$, and an oscillation frequency of $1 \mathrm{~Hz}$. The one-way shape memory experiment was performed in the stress-controlled mode, according to the literature. ${ }^{55}$ Samples (in tension with a preload force of $0.001 \mathrm{~N}$ ) were equilibrated at $60^{\circ} \mathrm{C}$. The samples were then elongated to a force of $0.024 \mathrm{~N}$ at a rate of $0.005 \mathrm{~N} \mathrm{~min}^{-1}$, cooled at a rate of $3{ }^{\circ} \mathrm{C} \mathrm{min}^{-1}$ to $0{ }^{\circ} \mathrm{C}$ in order to fix the elongated shape, and unloaded to $0.001 \mathrm{~N}$ using the same rate as before, $0.005 \mathrm{~N} \mathrm{~min}^{-1}$. The samples were then recovered by heating at the rate of $3{ }^{\circ} \mathrm{C} \mathrm{min}^{-1}$ to 60
${ }^{\circ} \mathrm{C}$. The shape fixity ratio, $R_{\mathrm{f}}$ and the shape recovery ratio, $R_{\mathrm{r}}$ are used to quantify the shape memory behavior. $R_{\mathrm{f}}$ is related to the fixation of the temporary shape and is a measure of the fixability of a mechanical deformation. $R_{\mathrm{r}}$ describes to what extent the original shape can be recovered. The percentage of shape fixing, $R_{\mathrm{f}}$, and shape recovery, $R_{\mathrm{r}}$ were calculated using the following equations. ${ }^{56,57}$

$$
\begin{aligned}
& R_{\mathrm{f}}(\%)=\left(\frac{\varepsilon_{\mathrm{u}}(N)}{\varepsilon_{\mathrm{i}}(N)}\right) 100 \\
& R_{r}(\%)=\left(\frac{\varepsilon_{\mathrm{u}}(N)-\varepsilon_{\mathrm{f}}(N)}{\varepsilon_{\mathrm{u}}(N)-\varepsilon_{\mathrm{f}}(N-1)}\right) 100
\end{aligned}
$$

Where $\varepsilon_{\mathrm{u}}$ is the strain obtained after releasing the applied load, $\varepsilon_{\mathrm{i}}$ is the initial strain before the load was released, and $\varepsilon_{\mathrm{f}}$ is the final strain after heating with no applied load, i.e., after maximum recovery of the deformation and $N$ is the number of cycles.

\section{RESULTS AND DISCUSSION}

3.1. Hypothesis, Design, and Synthesis. If the amorphous domains are selectively cross-linked, then the 


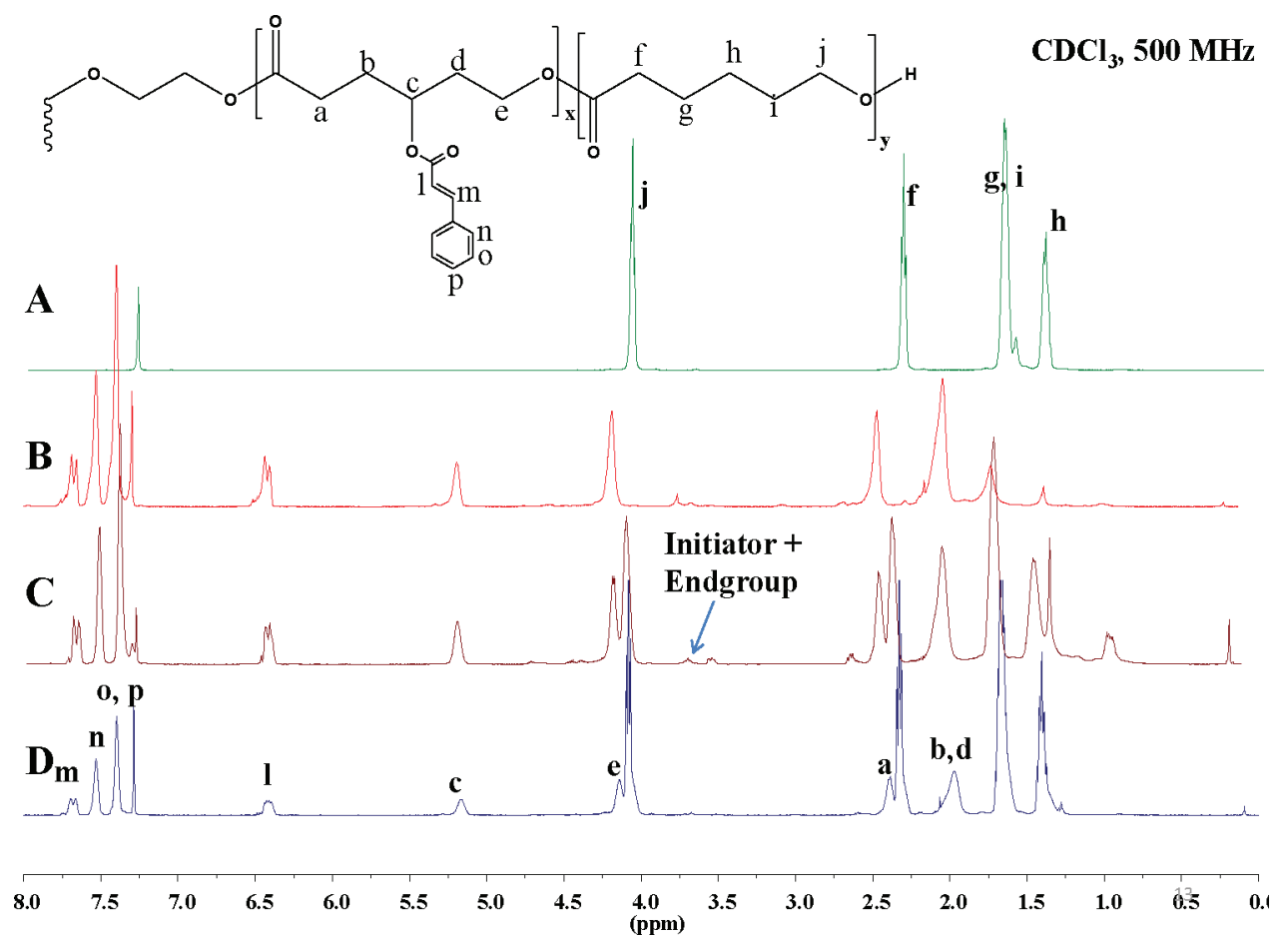

Figure 2. ${ }^{1} \mathrm{H}$ NMR spectra of the polymers (A) CL:CCL = 100:0, (B) CL:CCL $=0: 100,(\mathrm{C}) \mathrm{CL}: \mathrm{CCL}=50: 50$ random, (D) CL:CCL = 50:50 triblock.

crystalline domains are free to undergo a melting transition. Thus, we hypothesize that cross-linking can be used to set the permanent shape, and the melting transition can be used for shape memory programming and recovery (Scheme 3). Also, tuning of the transition temperature at which shape memory occurs can be accomplished by varying the molecular weight of PCL. We further hypothesize that synthesizing CCL, by modifying CL monomer with a cinnamate functional group, and then copolymerizing with CL will facilitate copolymers with enhanced properties such as hardness. ${ }^{58}$ Cross-linking with cinnamoyl moieties UV radiation is also useful for biomedical applications as it does not involve any initiator, cross-linker, chain extender or comonomer which can remain in the polymer and leach out during the degradation of PCL.

It is important to note here that while we did not test the reversibility of cross-linking, it has been reported that crosslinks formed from $[2+2]$ cycloadditions can be reversibly cleaved by UV irradiation $<260 \mathrm{~nm}$, leading to recovery of the original shape. ${ }^{1}$ In addition, the CCL sequences in the copolymer will disturb the crystallization process of the copolymer. Consequently an increase in the amount (and molecular weight) of modified monomer units in the copolymer will cause a decrease in the $T_{\mathrm{m}}$ because from a thermodynamic point of view, the entropy (and therefore the melting temperature) should be a smooth function of molecular weight as described by P. Flory. ${ }^{59}$

With the above hypotheses in mind, we propose a simple strategy to induce shape memory effect, which can be applied to semicrystalline polyesters in general.

The synthesis of the novel cinnamate-modified $\varepsilon$-caprolactone (CCL) monomer was accomplished in three steps. First, 1, 4-cyclohexanediol reacted with 0.5 equiv. of cinnamoyl chloride to yield product (A). The isolated alcohol (A) was then oxidized into the corresponding ketone $(\mathbf{B})$ by the use of pyridinum chlorochromate (PCC). Finally, the cyclohexanone
(B) was transformed into a final seven-membered lactone (C) by a Baeyer-Villiger oxidation using $m$-chloroperoxybenzoic acid (Scheme 1). The ${ }^{1} \mathrm{H}$ NMR spectrum of the cinnamate modified caprolactone monomer is shown in Figure 1, and the spectrum is consistent with the assigned structure. Homo, random, and sequential copolymerization of the CCL with CL was accomplished by ring-opening polymerization reaction using $\mathrm{Sn}(\mathrm{Oct})_{2}$ as the catalyst (Scheme 2).

3.2. Microstructure and Molecular Weight Analysis. The ${ }^{1} \mathrm{H}$ NMR spectra of the cinnamate-modified caprolactone (CCL) and the copolymers are shown in Figures 1 and 2, respectively. In Figure 1, the peak $d$ at $5.3 \mathrm{ppm}$ confirms the attachment of the cinnamate group in the monomer and in the copolymer shown in Figure 2 at $\delta=5.3 \mathrm{ppm}(\mathrm{c})$, which can be assigned to the new $-\mathrm{CHO}$ - bond of $\mathrm{CCL}$ along the main chain of the copolymer. The molar content of CCL in the copolymers was estimated by comparing the integrated signal of the $\alpha$-hydrogen atom of the CL $(e),(\delta=4.2 \mathrm{ppm})$ with the integrated signal of the $\alpha$-hydrogen atoms of CCL $(j),(\delta=4.1$ $\mathrm{ppm})$. The integrated signals of the $\gamma$-hydrogen atom of CCL $(\delta=5.3 \mathrm{ppm})$ are equal to those of the hydrogen atoms of the alkene group ( $\delta=6.4$ and $7.7 \mathrm{ppm}$ ) of the cinnamate group.

The relevant functional groups of cinnamate-modified caprolactone (CCL) and the corresponding copolymers were also confirmed using ATR IR as shown in Figures S.13 and S.14 (Supporting Information). These results indicate that cinnamate-modified caprolactone and copolymers of expected structures were successfully synthesized.

The molecular weight distribution and the polydispersity index $\left(M_{\mathrm{w}} / M_{\mathrm{n}}\right.$ or PDI $)$ of the copolymers were determined with GPC using a universal calibration curve (Table 1). The GPC chromatograms of the polymers showed a broad distribution as seen from the PDIs listed in Table 1. This $M_{n}$ was adequate to test our concept as uniform thin films were 
Table 1. Yield, Composition, and Molecular Weights of Copolymers of CL and CCL

\begin{tabular}{|c|c|c|c|c|c|}
\hline $\begin{array}{l}\text { copolymer } \\
(\mathrm{CL}: \mathrm{CCL})^{a}\end{array}$ & $\begin{array}{l}\text { reaction } \\
\text { time }(\mathrm{h})\end{array}$ & $\begin{array}{l}\text { yield }^{b} \\
\text { wt \%) }\end{array}$ & $\begin{array}{c}M_{\mathrm{n}}^{c} \\
\left(\mathrm{~g} \mathrm{~mol}^{-1}\right)\end{array}$ & $\begin{array}{l}M_{\mathrm{w}} /{ }_{c} \\
M_{\mathrm{n}}{ }^{c}\end{array}$ & $\begin{array}{l}\text { CCL in } \\
\text { polymer } \\
(\%)^{d}\end{array}$ \\
\hline 100:0 & 24 & 95 & 28000 & 2.40 & 0 \\
\hline 50:50 (triblock) & 24 & 60 & 8800 & 2.10 & 22 \\
\hline 50:50 (random) & 24 & 90 & 7100 & 1.58 & 45 \\
\hline $0: 100$ & 48 & 50 & 6670 & 1.61 & 100 \\
\hline $\begin{array}{l}\text { 50:50 (triblock } \\
\left.\operatorname{PCL}_{1250}\right)\end{array}$ & 24 & 70 & 11700 & 1.26 & 35 \\
\hline $\begin{array}{l}\text { 50:50 (triblock } \\
\text { PCL }\end{array}$ & 24 & 65 & 10100 & 1.10 & 25 \\
\hline
\end{tabular}

${ }^{a_{T}}$ The ratio of monomers in the feed, corresponding to the theoretical ratio of monomers in the polymer. ${ }^{b}$ Weight of polymer obtained after precipitation in cold methanol. ${ }^{c}$ Determined by GPC in THF using a universal calibration curve. ${ }^{d}$ Determined via integration of ${ }^{1} \mathrm{H} N M R$ spectra in $\mathrm{CDCl}_{3}$.

obtained for curing and testing of the mechanical and shape memory effect post curing.

Using anionic polymerization, polymers with controlled or desired molecular weight were expected. But because of side reactions such as transesterification reaction of the attached cinnamoyl group, low conversions were obtained and the polydispersity of the polymers was high. Although the conversion of CCL is significantly slower compared to the more reactive $\mathrm{CL}$ under the applied conditions, this alone cannot explain the results. It is postulated that the low conversion and high polydispersity are due to side reactions such as inter- and intra- transesterification of both the polyester backbone as well as the pendant cinnamate group.

To fine-tune and control the transition temperature (the temperature at which the polymer switches from a permanent shape to a temporary shape), we used PCL diols with $M_{\mathrm{w}} 1250$ and $2000 \mathrm{~g} \mathrm{~mol}^{-1}$ (molecular weight provided by the suppliers) as macroinitiators for copolymerization with CCL. The results of these polymerization are included in Table 1. Triblock copolymers with higher molecular weight and better polydispersity were obtained. The incorporation of CCL into the copolymer was similar to the previous triblock copolymer, i.e., the mol \% composition was similar.

3.3. Thermal Characterization of the Polymer Networks. Glass transition temperature $\left(T_{\mathrm{g}}\right)$, melting temperature $\left(T_{\mathrm{m}}\right)$, and latent heat of fusion $(\Delta H)$ of the copolymer films were determined using differential scanning calorimetry (DSC) (Figure 3). This analysis was performed because the melting temperature and crystallinity of the films play an important role in affecting the thermally induced shape memory effect described in the following section. Two heating and one cooling cycles were conducted for the photocured films at the heating and cooling rates of $10{ }^{\circ} \mathrm{C} \mathrm{min}{ }^{-1}$ in their respective directions. $T_{\mathrm{g}}, T_{\mathrm{m}}$, and $\Delta H$ with respect to the PCL segment in the copolymers are listed in Table 2 . Various architectures of copolymers showed different thermal behaviors. The random copolymer and the PCCL homopolymer did not show any melting transition. This is expected as the pendant cinnamate group interrupted the ordering and subsequent crystallization of the polymer chains. The triblock copolymer and the PCL homopolymer showed a melting transition. PCL is a semicrystalline polymer with a melting point at about $55{ }^{\circ} \mathrm{C}$. The presence of a melting transition $\left(T_{\mathrm{m}}\right)$ in the triblock copolymer

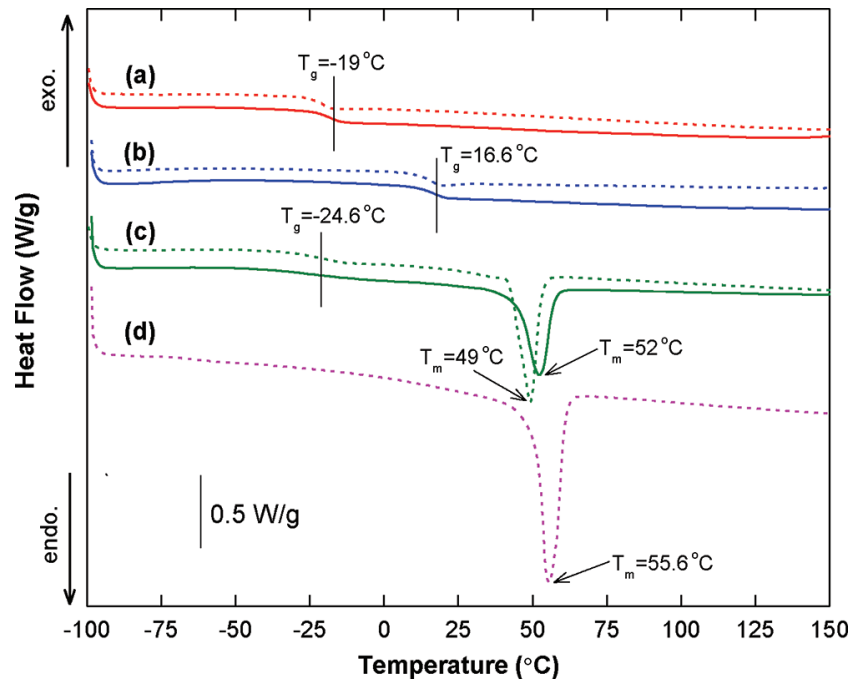

Figure 3. Representative DSC curves for the cured (solid lines) and uncured (dash lines) polymers. (a) CL:CCL $=50: 50$ random, (b) CL:CCL $=$ 0:100 homopolymer, (c) CL:CCL $=50: 50$ triblock, (d) $\mathrm{CL}: \mathrm{CCL}=100: 0$ homopolymer (2nd heating scan data). The heating rate was $10{ }^{\circ} \mathrm{C} \mathrm{min}^{-1}$ for all the samples.

Table 2. Thermal Properties and Gel Content of Photocured Films ${ }^{a}$

\begin{tabular}{|c|c|c|c|c|c|c|c|}
\hline \multirow[b]{2}{*}{$\begin{array}{l}\text { copolymer } \\
\text { (CL:CCL) }\end{array}$} & \multicolumn{2}{|c|}{$T_{\mathrm{g}}\left({ }^{\circ} \mathrm{C}\right)$} & \multicolumn{2}{|c|}{$T_{\mathrm{m}}\left({ }^{\circ} \mathrm{C}\right)$} & \multicolumn{2}{|c|}{$\Delta H\left(\mathrm{~J} \mathrm{~g}^{-1}\right)$} & \multirow[b]{2}{*}{$\begin{array}{c}\text { gel conten } \\
\text { (wt } \%)\end{array}$} \\
\hline & BXL & AXL & BXL & AXL & BXL & AXL & \\
\hline 50:50 (random) & -21 & -19 & & & & & 72 \\
\hline $0: 100$ & 16 & 16 & & & & & 70 \\
\hline 50:50(triblock) & -20 & -24 & 49 & 52 & 33 & 32 & 71 \\
\hline $100: 0^{b}$ & -64 & & 55 & & 72 & & 0 \\
\hline $\begin{array}{l}\text { 50:50 (triblock } \\
\mathrm{PCL}_{1250} \text { ) }\end{array}$ & -31 & -30 & 41 & 43 & & 11 & 75 \\
\hline 50:50 (triblock & -41 & -40 & 41 & 42 & & 36 & 77 \\
\hline
\end{tabular}

${ }^{a} \mathrm{BXL}$, before cross-linking; AXL, after cross-linking. ${ }^{b}$ Sample was not irradiated with UV light because there are no cross-linking groups in PCL homopolymer.

provides evidence for the presence of crystalline domains of PCL.

The thermal properties of the copolymers after photocuring were also studied to determine the effect of curing on $T_{\mathrm{m}}$. The $T_{\mathrm{m}}$ will be affected by the morphology and architecture of the polymer. This effect can be seen in Figure 3 as a shift of the melting point from 49 to $52{ }^{\circ} \mathrm{C}$ after cross-linking. This implies that the chain mobility is decreased because of cross-linking of the chain ends confirming triblock architecture with PCL domains in the middle and PCCL domains at the ends. The poly $(\mathrm{CL}: \mathrm{CCL})=80: 20$ triblock copolymer, gave a $T_{\mathrm{m}}$ at 54.4 ${ }^{\circ} \mathrm{C}$ which, as expected, is in between the PCCL homopolymer and poly $(\mathrm{CL}: \mathrm{CCL})=50: 50$ triblock copolymer, as shown in the Supporting Information, Figure S15.

The decrease in the heat of crystallization $(\Delta H)$ after crosslinking implies that the chains are unable to align after melting due to reduced chain end mobility. The block copolymers gave a $T_{\mathrm{g}}$ between the homopolymers of CL and CCL. The $T_{\mathrm{g}}$ increased with increasing CCL content. This implies that the amorphous domains of both polymers are miscible, which is expected as both chains have CL in the backbone. $T_{\mathrm{m}}, T_{\mathrm{g}}$, and $\Delta H$ values showed an overall increasing trend among the 
triblock copolymers with increasing $M_{\mathrm{w}}$ of PCL diol. This phenomenon is expected, as the chain mobility decreases with longer chain lengths.

3.4. Wide-Angle X-ray Analysis. WAXS azimuthally averaged intensity traces of cured polymers of $\mathrm{CL}: \mathrm{CCL}=$ 100:0 homopolymer, CL:CCL $=50: 50$ (triblock $\mathrm{PCL}_{2000}$ ) and $\mathrm{CL}: \mathrm{CCL}=50: 50$ (triblock) copolymers are shown in Figure 4.

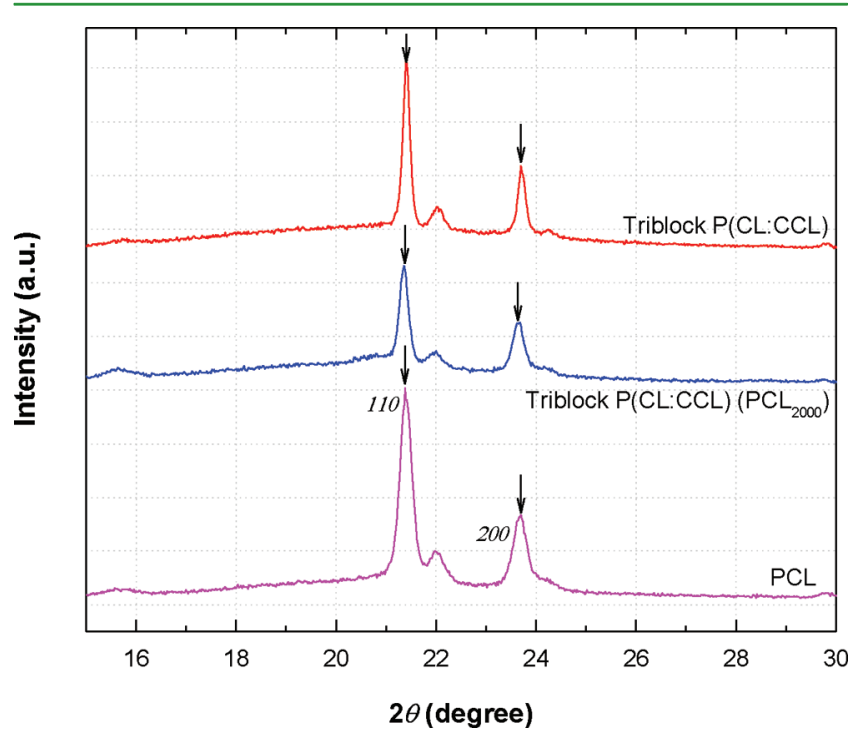

Figure 4. Wide-angle X-ray intensity (azimuthally averaged) traces for cured copolymers of CL:CCL $=50: 50$ (triblock), CL:CCL $=50: 50$ (triblock $\mathrm{PCL}_{2000}$ ) and CL:CCL $=100: 0$ homopolymer, which is not cross-linked. $\mathrm{Cu} \mathrm{K} \alpha$ radiation.

The WAXS patterns for all the samples show concentric and shape reflections with more or less amorphous background consistent with randomly oriented semicrystalline polymers. The PCL homopolymer shows very sharp crystalline reflections at $2 \theta=21.4^{\circ}(4.15 \AA)$ and $23.6^{\circ}(3.76 \AA)$, corresponding to the (110) and (200) lattice planes of an orthorhombic unit cell. ${ }^{49-54}$ The triblock copolymers also showed crystalline reflections for PCL but the $\mathrm{P}(\mathrm{CL}: \mathrm{CCL})$ (50:50) triblock gave tall, sharp peaks indicative of large crystallites, compared to the triblock obtained with $\mathrm{PCL}_{2000}$ which gave lower intensity and broader peaks indicative of small crystallites. The percent crystallinity in the polymers was calculated by summing the areas of all of the crystalline peaks and dividing that sum by the sum of the areas of all peaks (crystalline plus amorphous halo). It was easy to identify the amorphous halo in the peak list because it gave a large fwhm (several degrees, vs less than a degree for the crystalline peaks). The results are shown in Table 3 along with the corresponding degree of cystallinity, $X_{c}{ }^{D}$ obtained from DSC, using the corresponding enthalpy of melting and taking the heat of fusion of PCL to be $135 \mathrm{~J} \mathrm{~g}^{-1}$. In general, the second heating cycle of the DSC is taken for the $\Delta H$ and the \% crystallinity obtained is that of the material asprocessed. Even so, the $X_{c}{ }^{D}$ obtained from DSC is close to that obtained from WAXS. Indeed, we found a similar trend from both DSC and WAXS where the degree of cystallinity increased as the molecular weight of the PCL fraction increased.

3.5. Cross-linking of Polymers. The cinnamate group pendant to the polymer chains can be used for UV cross-linking of the polymer. Using UV light of $\lambda>260 \mathrm{~nm}$, the cinnamate group switches from the trans to the cis conformation. When two cis cinnamate groups react together, they undergo a $[2+2]$
Table 3. Degree of Crystallinity of PCL Homopolymer and the P(CL:CCL) Triblock Copolymers Obtained from WAXS and $\mathrm{DSC}^{a}$

\begin{tabular}{|c|c|c|c|c|}
\hline \multirow[b]{3}{*}{ polymer (CL:CCL) } & \multicolumn{2}{|c|}{ DSC } & \multicolumn{2}{|c|}{ WAXS } \\
\hline & \multicolumn{2}{|c|}{$X_{c}^{\mathrm{D}}(\%)$} & \multicolumn{2}{|c|}{$X_{c}^{\mathrm{X}}(\%)$} \\
\hline & BXL & $\mathrm{AXL}$ & BXL & AXL \\
\hline $100: 0^{b}$ & 53 & & 59 & \\
\hline 50:50(triblock) & 31 & 29 & & 29 \\
\hline 50:50 (triblock $\mathrm{PCL}_{2000}$ & & 53 & & 39 \\
\hline
\end{tabular}

${ }^{a} \mathrm{BXL}$, before cross-linking; AXL, after cros-linking. ${ }^{b}$ Sample was not irradiated with UV light because there are no cross-linking groups in PCL homopolymer.

cycloaddition reaction leading to the formation of a cyclobutane ring. This reaction is used to cross-link the polymer. The curing kinetics of the polymers were studied using UV-vis spectrophotometry by monitoring the absorption maximum at $280 \mathrm{~nm}$ which relates to the double bonds adjacent to carbonyl group of the cinnamate functionality, and the formation of a cyclobutane ring. Within $1 \mathrm{~h}$, almost $80 \%$ of the cinnamate groups disappeared, as seen in the UV-vis spectrum, with a decrease in intensity of the peaks at $280 \mathrm{~nm}$ (see the Supporting Information, Figures S.9-S.11).

The changes in the absorption spectra for the polymer films with increasing time of exposure are shown in Figure 5. The

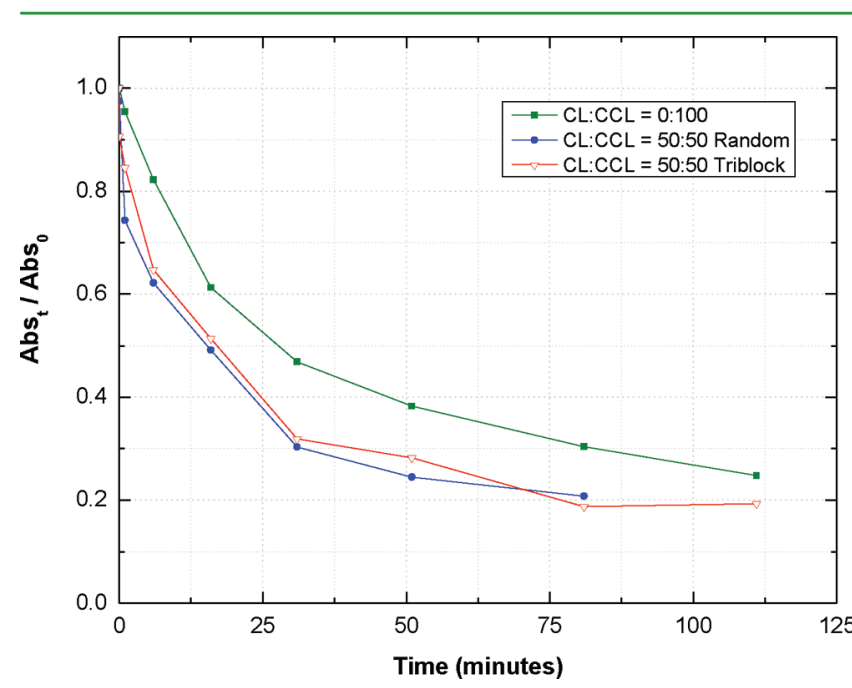

Figure 5. Changes in the normalized absorbance of polymer films at $280 \mathrm{~nm}$ upon irradiation with a UV lamp at ambient temperature. The UV intensity was $40 \mathrm{~mW} \mathrm{~cm}^{-2}$.

fast initial decrease in the normalized absorbance is characteristic of a polymer cross-linked through photocross-linking because the concentration of cinnamate groups is higher in the initial stages. As the cross-linking increases, concentration and mobility of the chains decreases leading to a plateau. The random and triblock copolymer showed a similar rate of cycloaddition. This behavior is expected as both polymers have similar glass transition temperatures. For the cycloaddition to occur, two cinnamate groups must be in close proximity to each other. Even though the random copolymer had more cinnamate groups, (Table 1) the mobility of the chains was found to be similar due to a similar glass transition temperature. For the homopolymer of CCL, the rate of cycloaddition is slower than the other copolymers because of its higher glass 
transition temperature. That is, to achieve $\sim 80 \%$ conversion, it took longer because with an increase in cycloaddition, the polymer chains became rigid because of high cross-linking. The fully cross-linked polymer was very brittle. To determine the extent of cycloaddition or extent of cross-linking, we immersed the films in acetone and the amount of extractable polymer was determined. All of the films gave a gel content of $\sim 70 \mathrm{wt} \%$, indicating that they had similar cross-linking densities. Investigating the role of the extent of cross-linking on the shape memory behavior was beyond the scope of this article and is not reported here.

3.6. Mechanical Properties. The mechanical properties of the cross-linked films were investigated to determine the effect of various architectures on the polymer properties. The representative stress-strain curves of the polymers are shown in Figures 6. The mechanical properties of the cross-linked

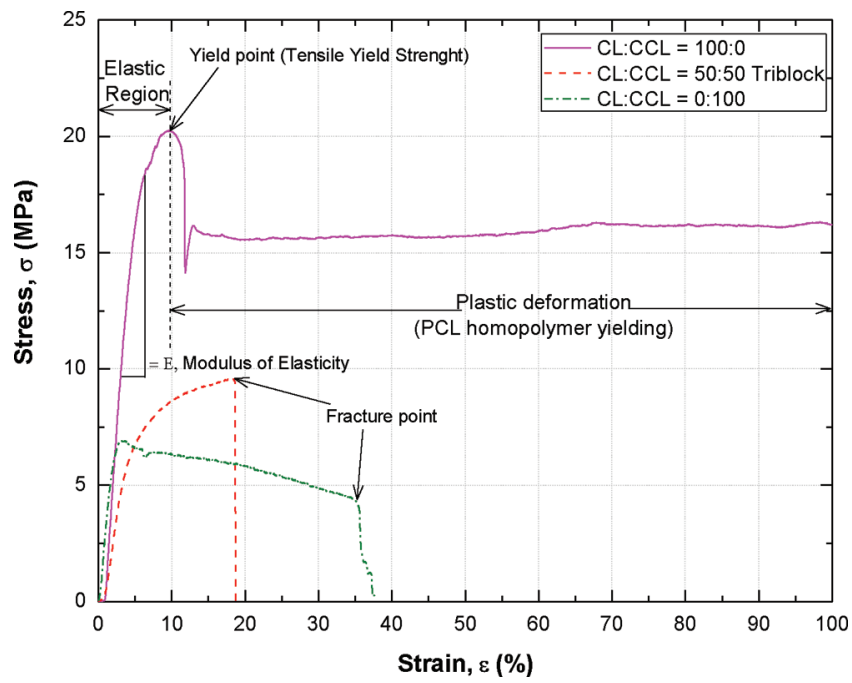

Figure 6. Stress-strain curves of the copolymers at room temperature.

polymers and un-cross-linked PCL film for comparison are listed in Table 4. Both the PCCL and triblock polymer films

Table 4. Tensile Properties of the Polymers at Room Temperature

$\begin{array}{lcccc}\begin{array}{c}\text { copolymer } \\ \text { (CL:CCL) }\end{array} & \begin{array}{c}\text { Young's } \\ \text { modulus, } E^{a} \\ (\mathrm{MPa})\end{array} & \begin{array}{c}\text { yield tensile } \\ \text { strength } \\ (\mathrm{MPa})\end{array} & \begin{array}{c}\text { ultimate tensile } \\ \text { strength }(\mathrm{MPa})\end{array} & \begin{array}{c}\text { maximum } \\ \text { elongation } \\ (\%)\end{array} \\ \begin{array}{l}\text { 100:0 } \\ \text { 5 }\end{array} & 511 \pm 83 & 20 & 15 \pm 1 & 110 \pm 33 \\ \begin{array}{c}\text { 50:50 } \\ \text { (triblock) }\end{array} & 223 \pm 17 & 10 & 9 \pm 1 & 19 \pm 3 \\ 0: 100 & 295 \pm 68 & 5 & 4 \pm 0.3 & 31 \pm 4\end{array}$

${ }^{a}$ Modulus calculated from the initial slope of the stress-strain curve. ${ }^{b}$ Sample was not irradiated with UV lamp because there are no crosslinking groups in PCL homopolymer.

displayed distinct yield strengths at 5 and $10 \mathrm{MPa}$, respectively and relatively low tensile strength compared to that of PCL with yield strength of $20 \mathrm{MPa}$. The higher modulus of un-crosslinked PCL is due to its higher molecular weight as shown in Table 1. The difference in modulus of PCCL and poly$(\mathrm{CL}: \mathrm{CCL})=50: 50$ triblock copolymer can be attributed to the lack of crystallinity in PCCL, since the molecular weight and extent of cross-linking (as measured by gel content determination) was similar. A similar decrease in tensile modulus is reported in the literature for PCL that is cross- linked with peroxide ${ }^{60}$ or UV light. ${ }^{28-30}$ Tensile properties of the random copolymer were not measured as the cross-linked polymer was soft and fracture of the sample occurred near the jaws, which invalidated the results.

3.7. Shape Memory Properties. Actuation of the shape transition is induced by heat. All the polymers synthesized showed very low glass transition temperatures, which are not suitable for on-demand shape memory transition for biomedical applications. Only the triblock copolymers showed a $T_{\mathrm{m}}$. Utilizing the melting temperature of the triblock copolymer as the transition or switching temperature, $T_{\text {trans }}$, the one-way shape memory effect was characterized. For shape programming and recovery, the thermomechanical cyclic experiments were performed in a stress-controlled mode according to the literature $^{55,61}$ along with the sequence described in the Experimental Section.

The three-dimensional (3D) test record for poly(CL:CCL) $=50: 50$ triblock copolymer-based networks is given in Figure 7 .

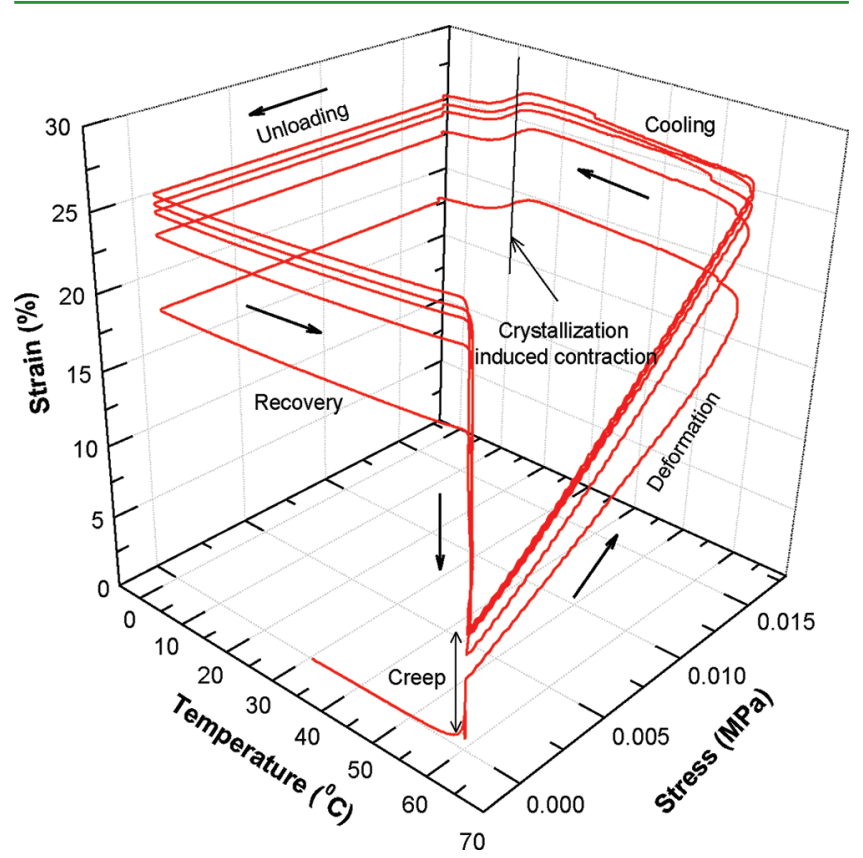

Figure 7. 3D diagram of $T_{\mathrm{m}}$-based one-way shape memory cycle for poly $(\mathrm{CL}: \mathrm{CCL})=50: 50$ triblock copolymer.

This shape memory cycle consists of four consecutive segments. In the first step, the sample is deformed at a temperature above $T_{\mathrm{m}}$ to $60{ }^{\circ} \mathrm{C}$, resulting in an increase of strain (deformation) from $19 \%$ in the first cycle to a maximum of $25 \%$ in the fifth cycle.

In the second step, the sample is cooled below $T_{\mathrm{m}}$ to $0{ }^{\circ} \mathrm{C}$ under constant tensile stress $(\sigma)$ to freeze the extended strain, $(\varepsilon)$ (cooling). The change in strain in this region is influenced by the temperature dependence of the coefficient of thermal expansion of the stretched polymer and volume effects that is based on the thermal transition at $T_{\text {trans }}$, e.g., a crystallization process. While cooling the sample, strain initially increases due to the creep response of the material under constant stress. As the temperature decreased below $20{ }^{\circ} \mathrm{C}$, the sample began to contract due to crystallization-induced contraction. The triblock copolymer has a crystallization temperature of $22{ }^{\circ} \mathrm{C}$. The strain then reached a plateau as the sample vitrifies below crystallization temperature. In the third step, the applied stress 
is reduced to the preload value $(0.001 \mathrm{~N})$ at $0{ }^{\circ} \mathrm{C}$, and the strain remains constant (unloading and shape fixing).

The mechanical movement in the course of the shapememory effect is so recorded as a function of the temperature. As indicated in Figure 7, the DMA cycles can differ from each other. With an increasing number of cycles the curves become more similar. The low recovery of the polymer in the first cycle is due to irreversible creep in the polymer after the first cycle. This creep increased slightly until the second cycle and remained approximately constant with each subsequent cycle. The process of deformation and recovery of the permanent shape becomes highly reproducible. The changes in the first cycles are attributed to the history of the sample piece. With respect to this, processing and storage play an important role. During the first cycles, a reorganization of the polymer on the molecular scale takes place. This is a reaction on the deformation in a certain direction. As seen from Table 5, the shape fixity $R_{\mathrm{f}}$ was excellent, with $\sim 99 \%$ of the initial strain retained after unloading of the stress.

Table 5. Strain, Shape Fixation $\left(R_{\mathrm{f}}\right)$, and Shape Recovery $\left(R_{r}\right)$ of Cross-linked Triblock Copolymer

$\begin{array}{ccccc}\text { cycle no. } & \text { strain }(\%) & R_{\mathrm{f}}(\%) & R_{\mathrm{r}}\left(1 \mathrm{st}^{a}\right. & R_{\mathrm{r}}(2 \mathrm{nd})^{a}(\%) \\ 1 & 18.9 & 98.7 & 59.9 & 65.6 \\ 2 & 23.5 & 99.0 & 80.4 & 92.7 \\ 3 & 24.9 & 99.0 & 83.8 & 98.9 \\ 4 & 25.4 & 99.1 & 84.2 & 99.4 \\ 5 & 26.0 & 99.0 & 85.1 & 99.6\end{array}$

${ }^{a} R_{\mathrm{r}}$ (1st): instantaneous recovery at $60{ }^{\circ} \mathrm{C}$. $R_{\mathrm{r}}(2 \mathrm{nd})$ : recovery after 30 min of isothermal heating at $60{ }^{\circ} \mathrm{C}$.

In the fourth step, the sample is now heated up to $T_{\text {high }}=60$ ${ }^{\circ} \mathrm{C}$ in a controlled way and the extended strain starts to recover when the temperature exceeds $T_{\mathrm{m}}$ of the sample (recovery). The temperature is held at $60{ }^{\circ} \mathrm{C}$ for additional $30 \mathrm{~min}$ to recover any residual strain (recovery). After the second cycle, the triblock showed excellent shape recovery $R_{\mathrm{r}}$ of $\sim 99 \%$ of the initial strain. Also seen in Table 5, two recovery rates are observed for the sample. The sample have very high initial recovery rate, $R_{\mathrm{r}}(1 \mathrm{st})$ with $\sim 85 \%$ of the strain recovered instantaneously. The recovery of the remaining strain is slow requiring $30 \mathrm{~min}$ of isothermal heating. The driving force for the sample recovery is the stress imposed on the material during shape programming. As the sample recovers, the driving force is decreased leading to a slow recovery. The slow recovery could also be attributed to irreversible deformation of the sample driven by the preload force.

To investigate this behavior, we performed DMA measurements above $T_{\mathrm{m}}$ and show them in Figure 8 as a plot of storage modulus, $E$ as a function of temperature. At $60{ }^{\circ} \mathrm{C}$, the sample has a modulus of $0.8 \mathrm{MPa}$. Thus, under a preload force of 0.001 $\mathrm{N}$, the deformation of the sample is rather small $(\sim 0.16 \%)$. Subsequently, the slow recovery is not due to deformation, but instead can be explained by dissipation of some of the stress by chain relaxation at temperatures above $T_{\mathrm{m}}$.

Cross-linking is necessary for shape memory transformation, if the highest transition temperature of the polymer is being used. In the triblock copolymers, shape memory behavior based on the $T_{\mathrm{m}}$ of PCL was successfully demonstrated. If instead, the $T_{\mathrm{g}}$ of the $\mathrm{P}(\mathrm{CL}: \mathrm{CCL})$ triblock copolymer was used for the trigger, then cross-linking would be unnecessary for the material to hold its permanent shape.

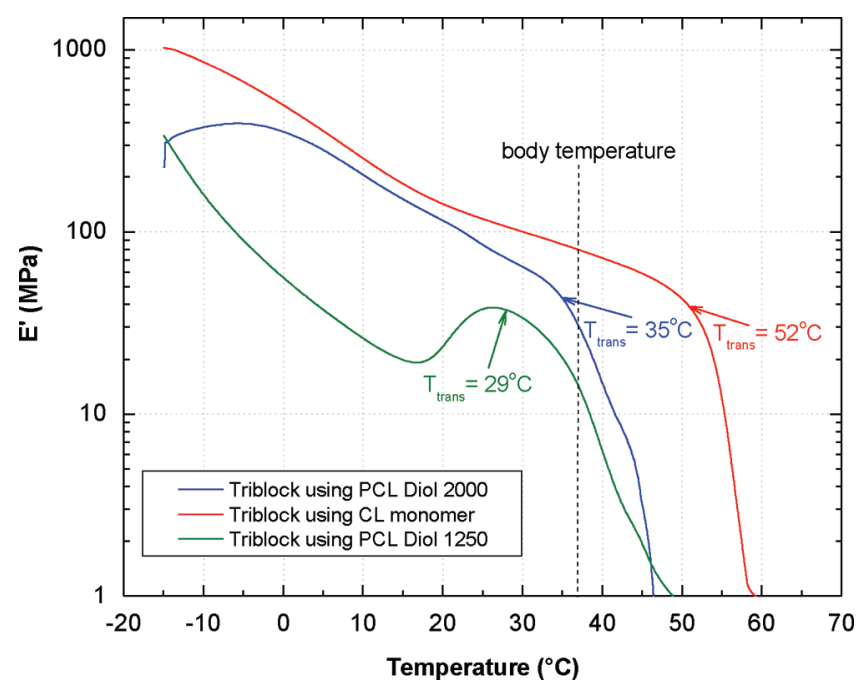

Figure 8. Thermomechanical experiments for triblock copolymers showing the tensile storage modulus $\left(E^{\prime}\right)$ measured using DMA at an oscillation frequency of $1 \mathrm{~Hz}$. The transition temperatures were found to be 29,35 , and $52{ }^{\circ} \mathrm{C}$ for the poly (50:50) triblocks prepared using $\mathrm{PCL}_{1250}$ diol, $\mathrm{PCL}_{2000}$ diol and $\mathrm{CL}$, respectively as comonomers with CCL monomer.

To confirm the above hypothesis, we performed "control" experiments using the un-cross-linked triblock copolymers and the cross-linked random copolymers. The un-cross-linked triblock copolymer was heated above $T_{\mathrm{m}}$; it melted and would not hold its shape as shown in the Supporting Information, Figure S18. Hence, thermomechanical cycling experiments using the DMA was not able to be performed with the un-cross-linked triblock copolymers. Similarly, the random copolymer also did not hold its shape at $60{ }^{\circ} \mathrm{C}$ and did not exhibit shape memory behavior either. These results confirmed our hypothesis that SMP systems in which the transition temperatures are closely based on the $T_{\mathrm{m}}$, both crystallinity and cross-linking are necessary to achieve a shape memory effect.

The dynamic mechanical behavior of the P(CL:CCL) (50:50) triblock copolymer networks were found to depend strongly on molecular weight of the PCL, as shown in Figure 8. The temperature at which the onset of decline in the tensile storage modulus occurs can be used as the transition temperature $\left(T_{\text {trans }}\right)$ for the shape memory effect. As expected, $T_{\text {trans }}$ increased as the molecular weight of the crystalline PCL segment increased. The ability to tune the switching temperature close to physiological temperature allows for biomedical applications of these SMP.

The representative $3 \mathrm{D}$ plots showing the shape memory cycles of the $\mathrm{P}(\mathrm{CL}: \mathrm{CCL})$ (50:50) triblock copolymers prepared using $\mathrm{PCL}_{2000}$ and $\mathrm{PCL}_{1250}$ diols are shown in the Supporting Information (see Figures $S 16$ and S17, respectively). The triblock copolymer prepared using $\mathrm{PCL}_{2000}$ gave very good shape memory effect at a strain of $\sim 28 \%$ with $\sim 99 \%$ shape fixation and $\sim 88 \%$ shape recovery after the second cycle. The triblock copolymer prepared using $\mathrm{PCL}_{1250}$, however, gave a low reversible strain $(\sim 1 \%)$. Regardless, it showed a shape memory effect, but because of its high rigidity, it did not show a good response. The reason for this poor response could be the low crystallinity and high cross-linking density of the polymer obtained, resulting in a copolymer with very low reversible strain. This system could be optimized by copolymerizing the end block with CL. This would increase the molecular weight 


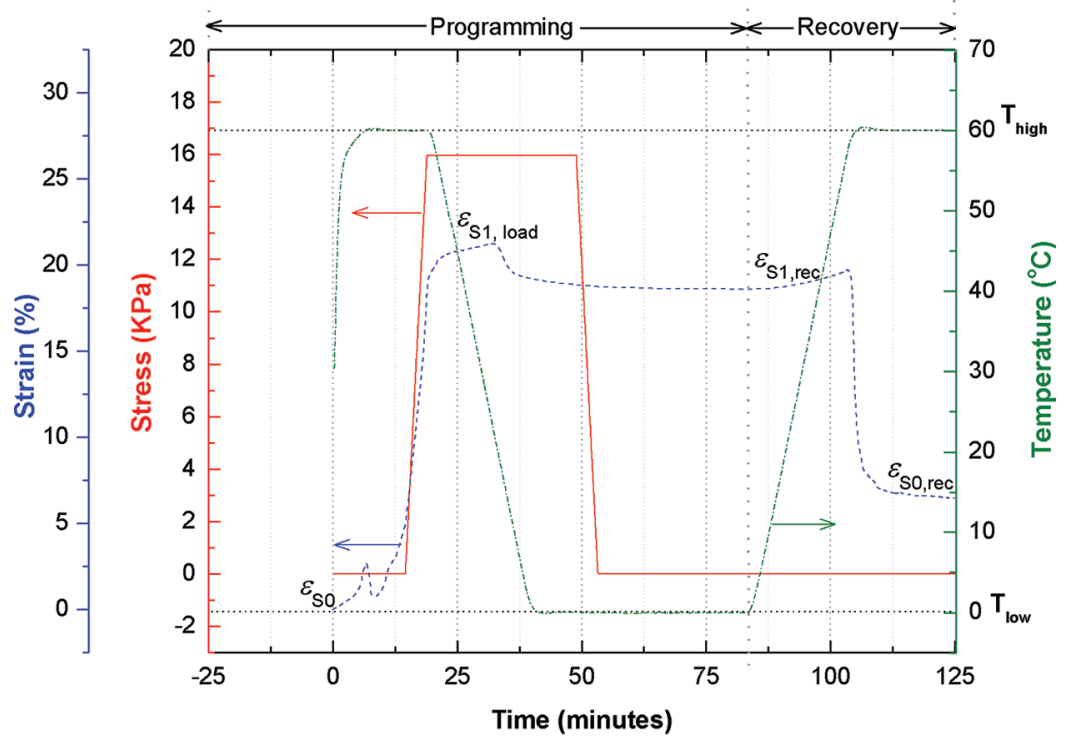

Figure 9. Cyclic, thermomechanical responses of poly $(\mathrm{CL}: \mathrm{CL})=50: 50$ triblock copolymer showing strain (blue), stress (red), and temperature (green) as a function of time illustrating the shape programming and recovery for a single cycle (1st cycle).
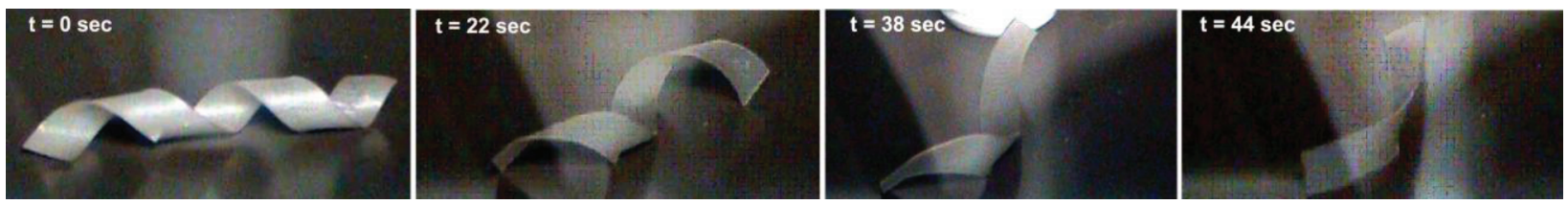

Figure 10. Photographs showing the sequential recovery of a poly (CL:CCL) $=50: 50$ triblock copolymer network from a temporary shape $(t=0 \mathrm{~s})$ to its permanent shape $(t=44 \mathrm{~s})$ in a convection oven maintained at $60{ }^{\circ} \mathrm{C}$. A video showing a faster recovery in a water bath is shown in the Supporting Information.

between cross-links and increase the reversible strain in the copolymer.

The strain as a function of time for the first cycle of the thermomechanical experiments in the above-mentioned temperature range is shown in Figure 9. The P(CL:CCL) (50:50) triblock is deformed from the permanent shape obtained after the second cycle to initial strain, $\varepsilon_{i}=19 \%$ at $T_{\text {high }}=60{ }^{\circ} \mathrm{C}$. Cooling to $T_{\text {low }}=0{ }^{\circ} \mathrm{C}$ under constant stress initially leads to an increase in strain caused by the entropy elasticity of the sample. After unloading at $T_{\text {low }}$, the sample was reheated to $T_{\text {high }}$, which led to the recovery of the permanent shape, the extent of which was determined by determining final strain, $\varepsilon_{\mathrm{f}}$. This experiment shows a dual shape capability of the amorphous CCL phase to fix a temporary shape as well as to allow the recovery of the permanent shape.

A visual demonstration showing the shape behavior of a representative poly $(\mathrm{CL}: \mathrm{CCL})=50: 50$ triblock copolymer is shown in Figure 10. A fully cured sample was cut into a rectangular film of dimensions $10 \mathrm{~mm} \times 2 \mathrm{~mm} \times 0.2 \mathrm{~mm}$. A protocol similar to the fixing method discussed in the above section was utilized for shape fixing, as we now describe. The sample was first placed in water at $60{ }^{\circ} \mathrm{C}$, allowed to equilibrate for $5 \mathrm{~min}$ and then removed and quickly manipulated by winding around a glass rod. It was then held in position until the sample equilibrated at room temperature $\left(\sim 22{ }^{\circ} \mathrm{C}\right)$. This led to fixing of the temporary shape (coil) as shown in Figure 10. The sample with the temporary shape (coil) was then placed into the oven at $60{ }^{\circ} \mathrm{C}$. Slow heating of the sample in the oven resulted in recovery to the permanent shape $(44 \mathrm{~s})$ which looks like a simple thermal relaxation. A better visualization of the recovery using a water bath at $60{ }^{\circ} \mathrm{C}$ can be seen in the video in the Supporting Information. The time-continuous movie shows a faster recovery process, where as soon as the sample touches the water, it returns to its original shape.

\section{CONCLUSIONS}

In this article, we describe the synthesis of a novel cinnamate modified lactone monomer, followed by copolymerization of this lactone with CL to form copolymers of various architectures, and the formation of cross-linked networks by UV curing with shape memory demonstration of the networks. One-way shape memory characterization was performed using DMA. The poly $(\mathrm{CL}: \mathrm{CCL})=50: 50$ triblock ABA copolymer with $\mathrm{CL}$ as the central block and CCL as the end blocks showed excellent shape memory effect with a high shape fixation, $R_{\mathrm{f}}(\sim 99 \%)$ and shape recovery ratio, $R_{\mathrm{r}}(\sim 99 \%)$ but a small strain of $\sim 25 \%$. The recovery of the shape is also fast with $\sim 85 \%$ of the strain recovered instantaneously. The dynamic mechanical behavior of the $\mathrm{P}(\mathrm{CL}: \mathrm{CCL})$ (50:50) triblock copolymer networks were found to depend strongly on molecular weight of the PCL. The temperature at which the onset of decline in the tensile storage modulus occurs can be used as the transition temperature $\left(T_{\text {trans }}\right)$ for the shape memory effect. As expected, $T_{\text {trans }}$ increased as the molecular weight of the crystalline PCL segment increased. The ability to tune the switching temperature close to physiological temperature allows for biomedical applications of these SMP. 
The novelty of these copolymers is that they are derived from a single biodegradable polymer system. The proposed strategy is a simple way of inducing the shape memory effect in various lactones, which can be used to obtain polymers with tunable transition temperature closer to application temperature by varying the molecular weight of crystalline domains and thus making this SMP more suitable for biomedical applications.

\section{ASSOCIATED CONTENT}

\section{S Supporting Information}

Figures showing ${ }^{1} \mathrm{H}$ and ${ }^{13} \mathrm{C}$ NMR spectrum of the monomer intermediates, ${ }^{1} \mathrm{H}$ NMR spectrum of copolymers, ATR IR spectra of the cinnamate modified caprolactone and the copolymers, UV-vis spectra of copolymers at different time intervals during curing and a DSC scan of the poly $(\mathrm{CL}: \mathrm{CCL})=$ 80:20 triblock copolymer and shape memory cycle experiments with cross-linked poly $(\mathrm{CL}: \mathrm{CCL})=50: 50$ triblock copolymer based on $\mathrm{PCL}_{2000}$ and $\mathrm{PCL}_{1250}$ diols. Cyclic, thermomechanical experiments for cross-linked and un-cross-linked poly$(\mathrm{CL}: \mathrm{CCL})=50: 50$ triblock copolymers performed using DMA. A time-continuous movie showing the sequential recovery process of the poly $(\mathrm{CL}: \mathrm{CCL})=50: 50$ triblock copolymer is also available. This material is available free of charge via the Internet at http://pubs.acs.org.

\section{AUTHOR INFORMATION}

\section{Corresponding Author}

*E-mail: Bridgette_Budhlall@uml.edu.

\section{Present Address}

${ }^{\S}$ Rajiv Gandhi Institute of Petroleum Technology, Raibareli, India 229316.

\section{ACKNOWLEDGMENTS}

The authors thank Meesha Kaushal for assisting with the sample preparation for the WAXS experiment; Dr. Eric Dunkerly for help with thermal characterization; Dr. Pallavi Kulkarni for help with compression molding of the films; Dr. Daniel Schmidt for performing the WAXS experiments and valuable discussions on the data analysis; the Center for HighRate Nanomanufacurturing for facilities support; the University of Massachusetts, Lowell, provost and commercial venture and intellectual property seed funds, the Massachusetts Technology Collaboration seed funds and the National Science Foundation, NSF (Award ECE \# 0425826) for financial support.

\section{REFERENCES}

(1) Lendlein, A.; Jiang, H.; Junger, O.; Langer, R. Nature 2005, 434, 879.

(2) Hribar, K. C.; Metter, R. B.; Ifkovits, J. L.; Troxler, T.; Burdick, J. A. Small 2009, 5, 1830.

(3) Ahir, S. V.; Terentjev, E. M. Nat. Mater. 2005, 4, 491.

(4) Liu, C.; Chun, S. B.; Mather, P. T.; Zheng, L.; Haley, E. H.; Coughlin, E. B. Macromolecules 2002, 35, 9868.

(5) Kunzelman, J.; Chung, T.; Mather, P. T.; Weder, C. J. Mater. Chem. 2008, 18, 1082.

(6) Mather, P. T.; Luo, X.; Rousseau, I. A. Annu. Rev. Mater. Res. 2009, 39, 445

(7) Osada, Y.; Gong, J.-P. Adv. Mater. 1998, 10, 827.

(8) Mohr, R.; K. K., T.; Weigel, M.; Lucka-Gabor, M.; Moneke; Lendlein, A. Proc. Natl. Acad. Sci. U.S.A. 2006, 103, 3540.

(9) W. M. Huang, B. Y.; Li, L. An, C.; Chan, Y. S. Appl. Phys. Lett. 2005, 86, 114105 .

(10) Zhang, H. D. J. Soft Matter 2010, 6, 7.
(11) Flory, P. J.; Rehner, J. J. Chem. Phys. 1943, 11, 512.

(12) Sosnowski, S. S.; Slomkowski, S. S.; Penczek, S. S. J. Macromol. Sci., Part A 1983, 20, 979.

(13) Takeuchi, D.; Nakamura, T.; Aida, T. Macromolecules 2000, 33, 725.

(14) Baśko, M.; Kubisa, P. J. Polym. Sci., Part A: Polym. Chem. 2006, 44, 7071.

(15) Hofman, A.; Szymański, R.; Słomkowski, S.; Penczek, S. Die Makromol. Chem. 1984, 185, 655-667.

(16) Detrembleur, C.; Mazza, M.; Halleux, O.; Lecomte, P.; Mecerreyes, D.; Hedrick, J. L.; Jerome, R. Macromolecules 1999, 33, 14

(17) Rana, S.; Lee, S.; Cho, J. Polym. Bull. 2010, 64, 401.

(18) Habnouni, S. E.; Darcos, V.; Coudane, J. Macromol. Rapid Commun. 2009, 30, 165.

(19) Raphaël Riva, L. C.; Robert Jérôme, P. L. ARKIVOC 2007, X, 292.

(20) Mecerreyes, D.; Humes, J.; Miller, R. D.; Hedrick, J. L.; Detrembleur, C.; Lecomte, P.; Jérôme, R.; Roman, J. S. Macromol. Rapid Commun. 2000, 21, 779.

(21) Sinnwell, S.; Ritter, H. Macromolecules 2006, 39, 2804.

(22) Liu, M.; Vladimirov, N.; Frechet, J. M. J. Macromolecules 1999, $32,6881$.

(23) Xue, L.; Dai, S.; Li, Z. Macromolecules 2009, 42, 964.

(24) Xue, L.; Dai, S.; Li, Z. Biomaterials 2010, 31, 8132.

(25) Zotzmann, J.; Behl, M.; Feng, Y.; Lendlein, A. Adv. Funct. Mater. 2010, 20, 3583.

(26) Lendlein, A.; Zotzmann, J. r.; Feng, Y.; Alteheld, A.; Kelch, S. Biomacromolecules 2009, 10, 975.

(27) Ping, P.; Wang, W.; Chen, X.; Jing, X. Biomacromolecules 2005, $6,587$.

(28) Nagata, M.; Sato, Y. J. Polym. Sci., Part A: Polym. Chem. 2005, 43, 2426.

(29) Nagata, M.; Kitazima, I. Colloid \& Polym. Sci. 2006, 284, 380.

(30) Nagata, M.; Yamamoto, Y. J. Polym. Sci., Part A: Polym. Chem. 2009, 47, 2422.

(31) Nagata, M.; Yamamoto, Y. Macromol. Chem. Phys. 2010, 211, 1826.

(32) Nagata, M.; Inaki, K. Eur. Polym. J. 2009, 45, 1111.

(33) Nagata, M.; Yamamoto, Y. React. Funct. Polym. 2008, 68, 915.

(34) Nagata, M.; Sugiura, R.; Sakai, W.; Tsutsumi, N. J. Appl. Polym. Sci. 2007, 106, 2885.

(35) Nagata, M.; Hizakae, S. J. Polym. Sci., Part A: Polym. Chem. 2003, 41, 2930.

(36) Zhu, G. M.; Xu, Q. Y.; Liang, G. Z.; Zhou, H. F. J. Appl. Polym. Sci. 2005, 95, 634.

(37) Zhu, G.; Xu, S.; Wang, J.; Zhang, L. Radiat. Phys. Chem. 2006, $75,443$.

(38) Zhou, J.; Schmidt, A. M.; Ritter, H. Macromolecules 2009, 43, 939.

(39) (a) Lee, K. M.; Knight, P. T.; Chung, T.; Mather, P. T. Macromolecules 2008, 41, 4730.

(40) Alvarado-Tenorio, B.; Romo-Uribe, A.; Mather, P. T. Macromolecules 2011, 44 (14), 5682-5692.

(41) Rodriguez, E. D.; Luo, X; Mather, P. T. ACS Appl. Mater. Interfaces 2011, 3, 152-161.

(42) Egerton, P. L.; Trigg, J.; Hyde, E. M.; Reiser, A. Macromolecules 1981, 14, 100.

(43) Nutley, B. P.; Farmer, P.; Caldwell, J. Food Chem. Toxicol. 1994, 32, 877.

(44) Belsito, D.; Bickers, D.; Bruze, M.; Calow, P.; Greim, H.; Hanifin, J. M.; Rogers, A. E.; Saurat, J. H.; Sipes, I. G.; Tagami, H. Food Chem. Toxicol. 2007, 45, S1.

(45) Kaneko, T.; Thi, T. H.; Shi, D. J.; Akashi, M. Nat. Mater. 2006, $5,966$.

(46) Matsusaki, M.; Hang Thi, T.; Kaneko, T.; Akashi, M. Biomaterials 2005, 26, 6263.

(47) Kaneko, T.; Tran, H. T.; Matsusaki, M.; Akashi, M. Chem. Mater. 2006, 18, 6220. 
(48) Kaneko, T.; Matsusaki, M.; Hang, T. T.; Akashi, M. Macromol. Rapid Commun. 2004, 25, 673.

(49) Huarng, J. C.; Min, K.; White, J. L. Polym. Eng. Sci. 1988, 28, $1590-1599$.

(50) Nishio, Y.; Manley, R. J. Polym. Eng. Sci. 1990, 30, 71-82.

(51) Nojima, S.; Hashizume, K.; Rohadi, A.; Sasaki, S. Polymer 1997, $38,2711-2718$.

(52) Chatani, Y.; Okita, Y.; Tadokoro, H.; Yamashita, Y. Polym. J. 1970, 1, 555-562.

(53) Bittinger, H.; Marchesault, H. Acta Crystallogr., Sect. B 1970, 26, 1923-1927.

(54) Hu, H.; Dorset, D. L. Macromolecules 1990, 23, 4604-4607.

(55) Rousseau, I. A.; Mather, P. T. J. Am. Chem. Soc. 2003, 125, 15300.

(56) Behl, M.; Lendlein, A. Mater. Today 2007, 10, 20.

(57) Rousseau, I. A. Polym. Eng. Sci. 2008, 48, 2075.

(58) Semba, T.; Kitagawa, K.; Ishiaku, U. S.; Hamada, H. J. Appl. Polym. Sci. 2006, 101, 1816.

(59) Flory, P. J. Trans. Faraday Soc. 1955, 51, 848.

(60) Koenig, M. F.; Huang, S. J. Polymer 1995, 36, 1877.

(61) Lendlein, A.; Langer, R. Science 2002, 296, 1673. 